Irish Math. Soc. Bulletin

Number 87, Summer 2021, 51-85

ISSN 0791-5578

\title{
Henry Perigal. Dissector, paradoxer, habitué of learned societies, and ornamental lathe turner extraordinaire
}

\author{
SEÁN M. STEWART
}

\begin{abstract}
The life and times of the little-known English amateur mathematician Henry Perigal and the role he played in British scientific society during the second half of nineteenth century makes for a very curious tale. Today best remember for his graceful and ingenious dissection proof for Pythagoras' theorem, his interests were principally geometric. These ranged from dissection methods, curves formed from compound circular motion, the ornamental arts enabling the mechanical realisation of geometric curves, to the obdurate belief he carried with him to the end concerning the motion of the moon and its lack of rotation on its axis as it orbited about the earth. In this paper we intent to throw light on this under-appreciated character who mixed at the very highest levels of Victorian England's scientific establishment but whose own achievements were far more modest.
\end{abstract}

\section{INTRODUCTION}

Friday, May 10, 1895 must have been a joyous occasion for Henry Perigal, the venerable old man of the London scientific establishment. For decades he had been a regular attendee at the Royal Institution's Friday Evening Discourses, but always as a 'visitor.' That evening would be his first as a Member, having earlier in the week been elected to the position [136, p. 564]. By then he was ninety-four years old - he is possibly the oldest person ever to have been elected a member - but despite his great age he continued to spend his evenings attending scientific meetings and lectures held throughout London.

So who was Henry Perigal, and what is he today best remembered for? Perigal was your archetypal Victorian scientific amateur. With his hobbies and interests being broadly geometric, he knew and moved amongst some of Britain's leading scientific figures of the second half of the nineteenth century. Even though his own scientific contributions were more modest - he was more curious philosopher than serious man of science - he played an important rôle over a period of several decades in the functioning of London's scientific establishment. Always most regular in his attendance at many of the scientific societies and learned institutions found throughout London, Perigal could be said to be the perfect embodiment of Victorian England's self-improvement ethos. Holding heterodox views about the motion of the moon, he spent a large part of his life attempting to convince others of the error of their ways. Many an ingenious device was built by him in an attempt to support his mistaken notion concerning the non-rotation of the moon. By the time of his death at the close of the nineteenth century, science, that once found a place for interested amateurs like Perigal, had moved on towards ever increasing specialisation dominated by professionals. In this article we sketch the life story of this most intriguing and colourful character.

2010 Mathematics Subject Classification. 01A55, 01A70.

Key words and phrases. Henry Perigal, dissection, Pythagoras' theorem, paradoxer, moon controversy, kinematic curves, geometric chuck.

Received on 26-10-2020. 


\section{BRIEF BIOGRAPHICAL SKETCH}

Born on the 1st of April, 1801, in Surrey, by the time he died on June 6, 1898 at the grand old age of 97 Perigal's life had spanned almost the entire nineteenth century. The eldest son of six children, he was named after his father, who lived for an impressive 99 years. As a result our Henry was known as Henry Perigal Junior until he himself was well into old age.

Little is known about Henry's early life and the type of education he received but it is thought to be consistent with that received by boys at the time from middle class families. It is not known if he attended university but it appears as though he did not as it is not mentioned in the account given for Henry in the Perigals' family history [88, pp. 40-41]. As a young man he worked for two years as a clerk in the Privy Council and afterwards in the old Victualling Office at Somerset House, rising to the level of chief clerk. After being pensioned off at an early age, he joined in 1844 the stockbroking firm of Messrs Henry Tudor and Sons at 29 Threadneedle Street, London, where the senior partner at the time was a personal friend of his. Here he worked as a clerk for many years before retiring in November 1888 at age 87 [40, pp. 387-388]. Though modestly employed, Perigal's long years of service at the same firm suggest he must have found the work agreeable. It was said he was a great believer in regular work, and friends found it difficult to induce him on occasion to leave the office for half a day [23]. He rarely left London and is thought never to have travelled abroad during the second half of his life, though in his younger days he did make a voyage to Madeira [76]. Starting from his time at Threadneedle Street, for the next forty odd years his life was one of routine, where he divided his time between days spent at the office and his evenings attending scientific meetings or lectures. He never married.

Perigal's scholarly output was sustained, though atypical for the time. He preferred to publish his work in pamphlet form instead of the more usual approach common in his day of submitting papers for publication in standard academic journals. These pamphlets were published mostly for private distribution among his friends and acquaintances. Occasionally they were also given as gifts to various scientific societies to which he belonged. This is unfortunate, as it makes locating and accessing Perigal's complete body of work difficult. The paucity in conventionally-published material is all the more unusual particularly for someone who belonged and engaged with so many leading scientific societies as Perigal did. We know of at least twenty pamphlets published by Perigal but as he was in the habit of publishing short single leaf communications the total number written is no doubt higher. One of his earliest known pamphlets was entitled 'Bow-pen drawings' [90]. A bow-pen is an instrument for drawing lines with ink. The work contained 91 drawings and was published in 1832. His last pamphlet appeared in 1894 [128].

Perigal's interest in geometric curves and mechanical devices used in their creation saw him producing many loose sheets filled with curves. The curves he was particularly drawn to were those resulting from compound circular motions [99]. These he published in profusion, and in his day they were what he was best known for. Tracking all these down is difficult, though we do know Perigal deposited at least three volumes of autographic copies of some of these printed sheets containing many of his curves with the Royal Society, Royal Institution, and Royal Astronomical Society [49].

Perigal is said to have been in good health right up until about 12 to 18 months before the end of his life. For example, on the occasion of the Astronomer Royal's 90th birthday celebration the 90-year-old Perigal was observed walking up the steep hill to the reception with 'almost a jaunty step.' [12]. At age 94 he visited the offices of the monthly popular-science magazine Science-Gossip, and the proprietor and then editor John T. Carrington was amazed when Perigal avoided the passenger lift with scorn, 
preferring instead to make his ascent to Carrington's office by mounting several flights of stairs [22].

Later in life Perigal allowed his beard and hair to grow long and in appearance looked the quintessential gentleman philosopher. Despite the somewhat heterodoxical views he held regarding the motion of the moon, his gentle demeanour, unwavering commitment to service, and endearing personal character won him a place in the highest echelons of nineteenth century British scientific society. As testament of this his passing was a great loss and noted by many $[14,15,16,17,18,19,20,21,22,23,76,28,138,142,134]$.

\section{LEARNED SOCIETIES OF LONDON}

Henry Perigal was very much the embodiment of the Victorian era with its particular attention to self-improvement. In his case his own attempts at self-improvement were channelled into his sustained association with numerous scientific societies located in London over the course of his long life. His unwavering commitment and constancy in attending meetings was legendary. This he maintained throughout the course of his life right up until about 12 months before his death. Later in his life people wrote how they found it quite extraordinary that for someone of such a great age it was possible to maintain his strict, regimental attendance given it required him to be up to quite late on most evenings of the week [13]. Such was the regularity of his attendance, in his later years he would be universally referred to as the 'venerable' old figure of London's scientific scene. Indeed, so regular was his attendance at such meets over the course of so many years that his sudden absence just before his ninety-sixth birthday brought great cause for concern [129]. His death was said to have left a terrible blank among the regular attendants at the many scientific societies to which he belonged [28]. Many years later the Scottish geographer and meteorologist Hugh Robert Mill (1861-1950) recalled how when he was young, on the occasion of reading his first paper before the Royal Meteorological Society the patriarchal figure of Perigal was quietly seated in the audience. He writes he was then in his eighty-seventh year and '... had long been one of the landmarks of the evening meetings.' [84, p. 323].

It is difficult to count exactly the many learned societies to which Perigal belonged. Table 1 gives a list of those known. For three of these societies he was a Fellow, the highest rank any society can bestow upon its members. As a Fellow he would have been entitled to use three different sets of post-nominal letters after his name: FRAS (Fellow of the Royal Astronomical Society), FRMetSoc (Fellow of the Royal Meteorological Society), and FRMS (Fellow of the Royal Microscopical Society). Of the three, he is found using the first on almost all occasions, the second occasionally, and the third only rarely. However, as alluded to in our opening introduction, the membership he was most proud of was that of the Royal Institution, attained after attending loyally for many years the Institution's Friday Evening Discourses. On his election this would have further entitled him to use the designatory letters MRI (Member of the Royal Institution).

Of all the societies to which Perigal belonged he had the closest association with the Royal Meteorological Society. After joining what was then the British Meteorological Society a few months after its foundation on 3 April 1850, he was appointed its Treasurer on May 24, 1853, a position he held continuously for just over 45 years until the time of his death [141]. By the time of his death the society had changed its name twice. The first change was to The Meteorological Society in 1866, when it was incorporated by Royal Charter, and then to the Royal Meteorological Society in 1883 when the privilege of adding 'Royal' to the title was granted. Indeed, longevity amongst meteorologist seemed to be a prerogative of theirs and was often the subject of comment $[187,36]$. 


\begin{tabular}{l|l}
\hline Name of learned society & Date joined/elected \\
\hline $\begin{array}{l}\text { Society for the Encouragement of Arts, } \\
\text { Manufactures and Commerce }\end{array}$ & April 17, 1823 \\
Royal Astronomical Society & $\begin{array}{l}\text { Joined, date unknown } \\
\text { Fellow, February 8, 1850 }\end{array}$ \\
Royal Meteorological Society & June 4, 1850 \\
& Fellow, December 22, 1851 \\
Royal Microscopical Society & 1852 \\
Royal Aeronautical Society & Fellow, date unknown \\
London Mathematical Society & 12 February, 1866 \\
Amateur Mechanical Society & January 23,1868 \\
Physical Society of London & January 1,1869 \\
Association for the Improvement & February, 1874 \\
of Geometric Teaching & January, 1874 \\
Quekett Microscopical Club & \\
British Astronomical Association & July 22, 1881 \\
Royal Institution & November 15,1890 \\
Camera Club & Member, May 6,1895 \\
\hline
\end{tabular}

TABle 1. A list of those learned societies to which Henry Perigal is known to have belonged and the date when he joined, if known. To those societies where he was a Fellow, his date of election, if known, is indicated.

For example, the father of English meteorology and 'godfather of clouds,' Luke Howard, lived to 92, and Perigal's close friend the English meteorologist James Glaisher lived to 94.

The gratitude the Society felt to Perigal for his lengthy term of service can be seen in the recognition it bestowed upon him. In addition to being a Fellow, on April 15, 1893, a complimentary dinner was held by the Society in his honour marking the occasion of his ninety-second birthday and his forty years of service as Treasurer [139, 140]. A week after his death at the June 15 meeting a resolution was moved and unanimously adopted that in part recorded the Society's desire to recognise the valuable service Perigal had rendered to the Society over so many years and the keen interest "which he took in the discharge of his duties.' [141]. The following year a photograph of Perigal appeared as a frontispiece in the July 1899 issue of the society's journal, the Quarterly Journal of the Royal Meteorological Society [143]. This is reproduced in figure 1. It is a photograph taken by the German-born English engineer and photographer John Matthias Augustus Stroh (1828-1914) in 1890 when Perigal was aged 89. Also in the same year, as part of welcoming the Fellows to the new offices of the Society, the President held what was then known as an 'At Home.' This was a Victorian British social custom where the host would be available to receive visitors on a specific day of the week, hence they were 'at home.' In addition to two demonstrations of the optical lantern being held and 
refreshments served, a number of rooms exhibiting various instruments, photographs, awards, and other items of memorabilia had been set up. Of the total of 93 items on display that evening one was a photograph of Perigal, another a portrait of him, and the third a plaque in his honour [144]. It was a fitting tribute to a man who had given such a large part of his life in service to the society.

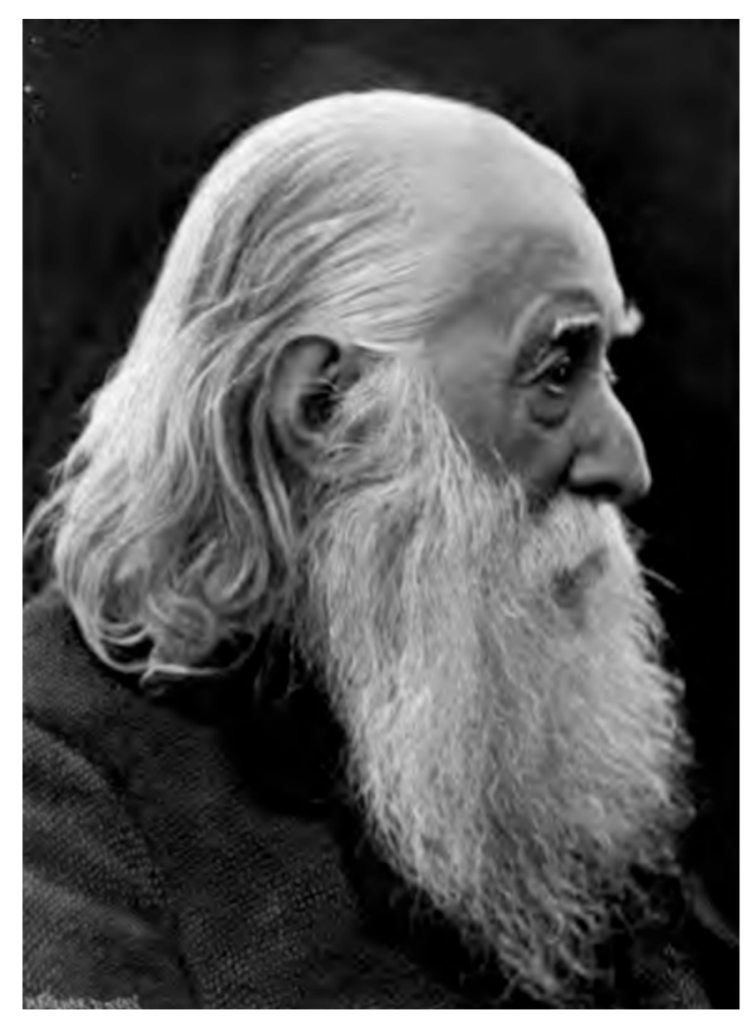

Figure 1. A photograph of Henry Perigal which appeared as the frontispiece to the July 1899 issue of the Quarterly Journal of the Royal Meteorological Society [143].

Despite the large number of learned and scientific societies to which Perigal belonged the one he most coveted was only available to members through election. It was the oldest and most revered of all the learned societies in the country. It was of course the Royal Society. Founded in 1660 its members, all of whom are Fellows, must nominate for election into the Society. Perigal put his name forward on three separate occasions starting in 1853 [147]. Unsuccessful, he followed this up in 1854 and again in 1855 without success [148]. Many years later in his recollections about his older brother, Frederick Perigal (1812-1905) wrote that while his brother believed his investigations into compound circular motion, the many mechanical devices he built, together with his numerous other scientific accomplishments merited election, he was only too aware he would be judged harshly considering the unorthodox views he held regarding the motion of the moon [89]. We shall return below to these apsects of Perigal's life.

Perigal did manage to gain election to the Royal Astronomical Society Club, an inner circle of the Royal Astronomical Society. In this case the unorthodox views Perigal held about the motion of the moon were, oddly, not enough to prevent his election. Numbers to the Club were strictly limited and not all Fellows of the Society, to which Perigal had been elected on February 8, 1850, were Club members. A number of benefits open to members of the Club not available to others included dining together on the days when the Society met [185]. Perigal was elected to the Club on June 17, 1853, and in what 
would later prove to be an ironic twist, his proposer was the English mathematician Augustus de Morgan (1806-1871). I say ironic as it would be de Morgan who a decade later called attention to Perigal's denial of the moon's motion on her axis.

Like all the societies to which Perigal belonged he was a regular attendee at the London Mathematical Society meetings. He was elected a member on January 23, 1868. On his passing, the then president of the society, Edwin Bailey Elliott (18511937), wrote that even though very little flowed from his pen into the society's journal of record Perigal's frequent attendance had helped make their gatherings occasions for the informal exchange of ideas and acted as a source of stimulation for those who had the 'cause of mathematics at their heart.' [51]. Though this had been one of the stated aims of the Society in its younger days Elliott lamented that the place for the curious amateur at their meetings for people like Perigal had by the dawn of the twentieth century largely been lost.

The London Mathematical Society had been established in January 1865. When it formed Perigal would have very much liked to have joined immediately but feared his heterodoxical views on the motion of the moon would disqualify him. He was much relieved when three years later de Morgan, who was not only the first president of the Society but was coming to his rescue for a second time, offered to put his name forward and signed his nomination form [76].

Perigal's long association with the Royal Microscopical Society is an interesting one. Though the microscopy had never been so great an interest of his compared to astronomy or geometry, Perigal always took the keenest interest in the proceedings of the society, even more so once he stop regularly attending the society's meetings due to his failing health. His good friend, wharfinger, amateur scientist, and fellow member of the Royal Microscopical Society, John Jewell Vezey (1844-1906) was in the habit of paying his friend Perigal a weekly visit for many years later in his life. Vezey recounts how Perigal was always most eager to hear about the latest developments and goings on in the scientific world [146]. Though in late 1896 Perigal had recently complained to his friend that his memory for details had started to fail him unless it concerned particular areas of interest where he had worked [145], his intellectual curiosity never ceased to disappear despite his advancing age and fading mind.

\section{A Dissection for the AGeS}

Today if Perigal is remember at all it is for the elegant dissection proof he gave for Pythagoras' theorem. Nowadays dissections are a beautiful area of recreational mathematics largely inhabited by amateur mathematicians. Dissection problems call for the cutting of one or more figures into pieces that can be rearranged to form other figures in a way areas are preserved. Dissections are often cast as puzzles, in which case the object is usually to find as few pieces as possible, or used as elementary ocular demonstrations proving results about the equivalence of areas. Perigal's Pythagorean dissection is ostensibly a dissection problem about how two smaller unequal squares can be cut and reassembled using all pieces to form a single larger square. Finding such a dissection immediately gives one a proof for Proposition 47 found in Book 1 of Euclid's Elements, the most famous theorem in perhaps all of mathematics, that of Pythagoras' theorem.

That this is the case, consider a right-angled triangle whose hypotenuse has length $c$ with the other two sides of lengths $a$ and $b$. Forming squares of equal lengths on each side of the right-angled triangle we see the area of each square will be $a^{2}, b^{2}$, and $c^{2}$ such that for the three areas one must have $a^{2}+b^{2}=c^{2}$ in accordance with Pythagoras' theorem. While many such dissections are possible, what makes Perigal's dissection so special is the simplicity of its construction and the sheer elegance of its final form. It 
consists of five pieces, four coming from the larger of the two squares with each of the pieces congruent to each other while the fifth piece comes from the smaller square and is not divided. When formed into a single larger square the positions of the five pieces possess four-fold symmetry. It is truly a dissection for the ages.

Perigal tells us he came across his dissection in 1830 while attempting to square the circle [121, p. 103]. Squaring the circle is impossible since $\pi$ is transcendental, as was proved in 1882 by the German mathematician Ferdinand von Lindemann (1852-1939) [73] several decades after Perigal first starting working on the problem. Even after Lindemann's result had shown the impossibility of squaring the circle, it seems Perigal remained unconvinced. In the minutes of a meeting held by the London Mathematical Society on April 12, 1894, we are told that, quite extraordinarily, Perigal had presented some diagrams illustrating circle squaring by dissection [75].

What has today become known as Perigal's dissection is given in figure 2. What should be immediately obvious is the overall charm of the dissection. Using as many identical pieces that are as few in number as possible the resultant high degree of symmetry is what gives the dissection its elegance. Seeing this dissection for the first time is for many sure to be a memorable occasion. It certainly was for this author.
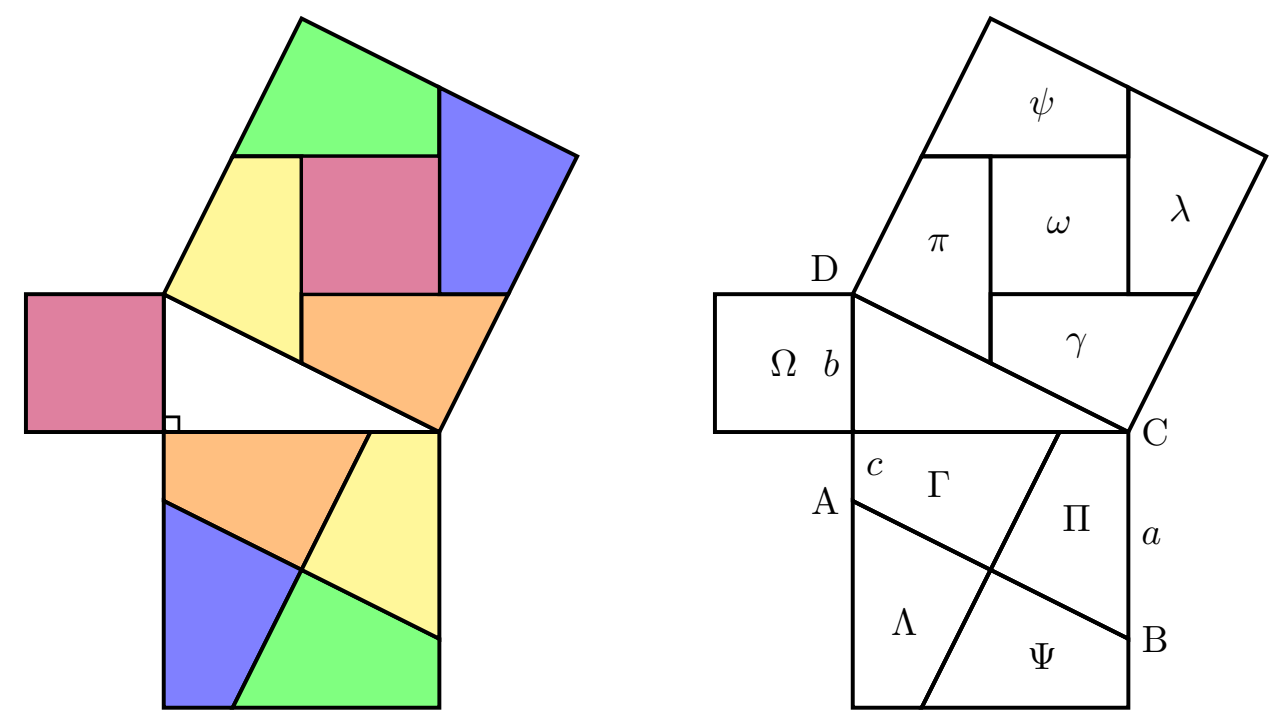

Figure 2. Left: Perigal's famous dissection that gives a proof of Pythagoras' theorem. Right: Perigal's dissection now labelled to be used in the proof showing the congruence of areas.

The construction used for the dissection is quite simple. For a given right-angled triangle, on each of its sides draw a square. For the square sharing the longer side of the triangle which is not the hypotenuse locate its centre, the point where the two diagonals of the square intersect. Draw a line which is parallel to the hypotenuse of the triangle passing through the centre of the square just found. Next draw a line that passes through the same centre of the square that is perpendicular to the previous line just drawn. The square is now divided into four equal quadrilaterals as shown in figure 2. The square appearing on the shortest side of the triangle in not dissected. The five pieces can then be translated, without rotating or reflecting any piece, and fitted exactly into the largest square appearing on the hypotenuse of the right-angled triangle, as indicated in the top square appearing in the figure.

For a proof of this one needs to show the dissection of the square into four congruent pieces together with the smallest square can be assembled to make up the largest square. 
The proof we present follows very closely that originally given by Perigal. For an algebraic proof, see [44]. We will use the labelled diagram appearing on the right in figure 2. By construction $\mathrm{AB}$ is parallel to the hypotenuse $\mathrm{CD}$ and $\mathrm{AD}$ is parallel to $\mathrm{BC}$. Thus $\mathrm{ABCD}$ is a parallelogram with $\mathrm{AD}=\mathrm{BC}$ or $a=b+c$. The two construction lines that pass through the centre of the square on the major leg of the triangle are equal in length to the hypotenuse. Since the two construction lines passing through the centre intersect one another at right angles they are bisected. Two of the four sides of quadrilaterals $\Gamma, \Pi, \Psi$, and $\Lambda$ are therefore equal to half the hypotenuse. As all sides of quadrilaterals $\Gamma$ and $\gamma$ are parallel and as two of the sides of the latter quadrilateral are equal to half the side of the square located on the hypotenuse, quadrilaterals $\Gamma$ and $\gamma$ are congruent. In a similar manner the congruence between quadrilaterals $\Lambda$ and $\lambda$, $\Pi$ and $\pi$, and $\Psi$ and $\psi$ can be shown. Now it remains to prove the congruence between the quadrilateral $\omega$ and the square $\Omega$. The longest side of quadrilateral $\gamma$ is equal to $a$. The shortest side in quadrilateral $\lambda$ is equal to $c$. Thus the length of one side of quadrilateral $\omega$ is equal to $a-c=b$. In a similar manner it can be shown all sides of quadrilateral $\omega$ are equal to $b$. Finally, as the angle between the longest and shortest sides in quadrilateral $\gamma$ is a right angle, the adjacent angle in quadrilateral $\omega$ is also a right angle as the two angles are supplementary. In a similar manner it can be shown all internal angles within quadrilateral $\omega$ are equal to right angles. Thus $\omega$ is a square congruent with $\Omega$ and completes the proof.

Perigal was obviously well pleased with his discovery. So much so that for a time he used a picture of the dissection on the front of his visiting cards (see figure 3). Work on this and other dissections he had found were drawn up and published in 1835 as a pamphlet for private circulation among his friends [91]. This was unfortunate as its limited distribution meant not many people were aware of this most exquisite dissection, despite Perigal's best efforts - he gave hundreds away as a curious dissection puzzle [121].

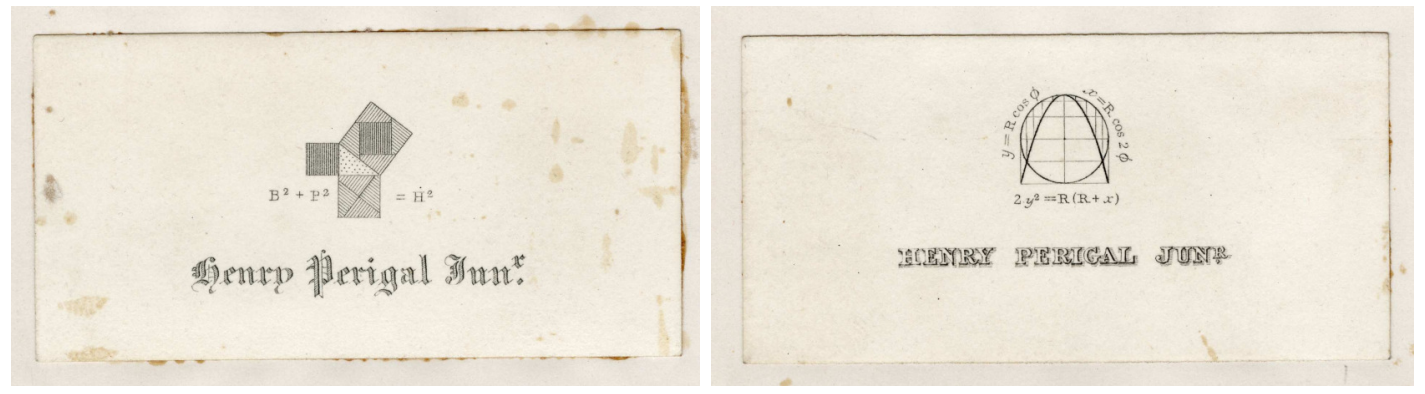

Figure 3. Some visiting cards of Henry Perigal. Photographs courtesy of the author.

Perigal does not tell us exactly how the discovery of his dissection came to be other than it was somehow found during the course of his attempts to square the circle. Perhaps it was one of serendipity. What is certain is it would be his greatest scientific accomplishment and is the reason why his name has come down to us today. Not realised by Perigal at the time is the fact that his dissection can be readily obtained by taking a tessellation of the two smaller squares and overlying it with a tessellation of the largest square that is formed on the hypotenuse of the right-angled triangle. This is shown in figure 4 . If one tessellation is moved relative to the other a continuous family of dissection proofs for Pythagoras' theorem emerge. This was apparently first pointed out by the German mathematician Friedrich Paul Mahlo (1883-1971) in 1908 as part of his doctoral dissertation [80] and later independently by others including the English 
mathematician Major Percy Alexander MacMahon (1854-1929) [79] and the English mathematician and educationist Arthur Warry Siddons (1876-1959) following a suggestion sent to him by a sixteen year old girl named M. Charlesworth [155]. Also not realised by Perigal was his dissection is completely hingeable, something not recognised until the late 1980s by the mathematician David Singmaster [58, pp. 33-34]. This is shown in figure 5. Swinging the square appearing on the right in an anticlockwise direction, two unequal squares are formed with the two formed squares obviously attached to each other at a single hinge point while swinging the square in a clockwise direction forms one single larger square.

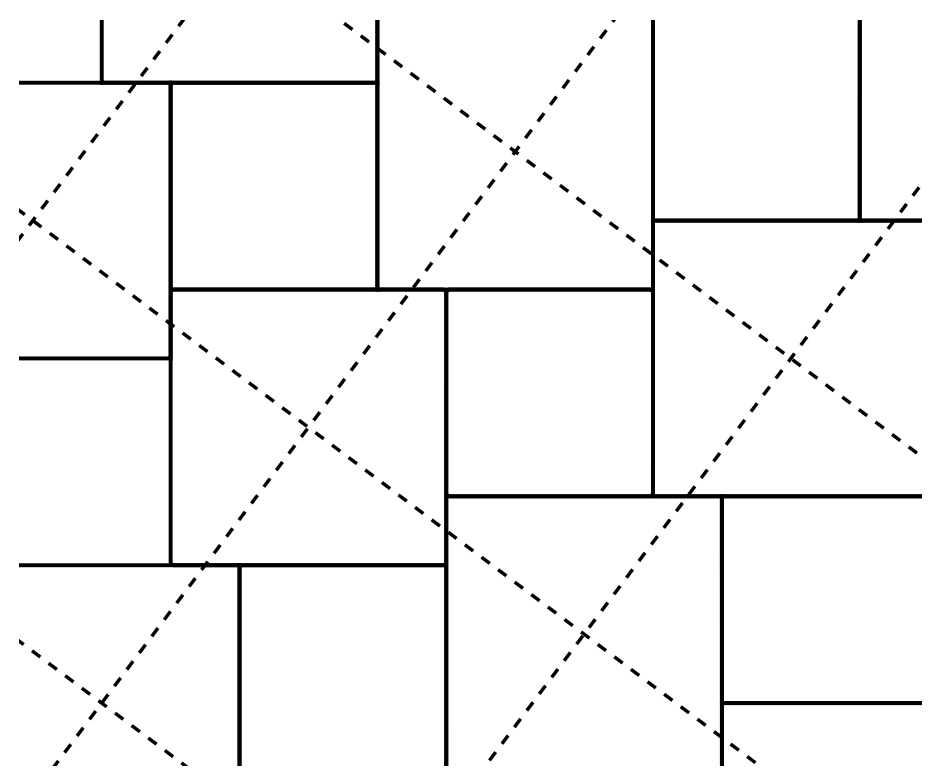

Figure 4. Perigal's Pythagorean dissection resulting from a superposition between two tessellations.

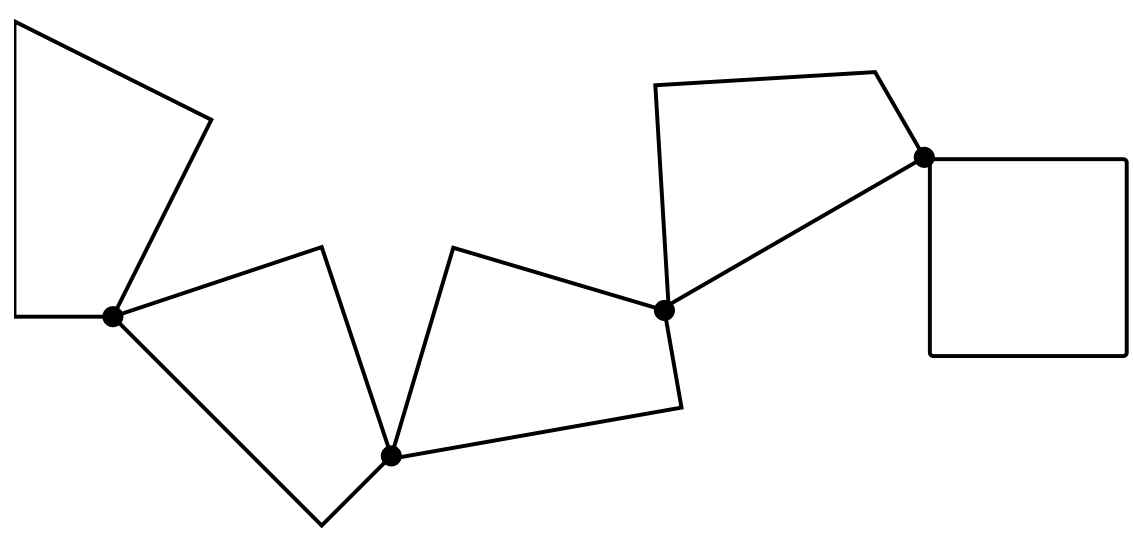

Figure 5. Perigal's Pythagorean dissection in hingeable form.

A close friend of Perigal's for many years was the English meteorologist, aeronaut, and astronomer James Glaisher (1809-1903). They first met in 1855 [76, p. 735]. It was Glaisher's son, the mathematician James Whitbread Lee Glaisher (1848-1928), who some forty years later as editor-in-chief of the journal Messenger of Mathematics, on seeing a selection of Perigal's geometric dissections encouraged him to publish some 
of these in the Messenger. This Perigal duly did with his first paper appearing in the November 1872 issue of the Messenger [121]. As the journal was only in its second year of publication it is likely Glaisher had been looking out for suitable material to publish in his fledgling journal, and father must have mentioned to son that his old friend Perigal may have something of interest. With Perigal's first paper on geometric dissections Glaisher would not be disappointed. It contained what Perigal describes as his best geometric dissection. At the conclusion of the paper, in an editorial, Glaisher commented how struck he was by the elegance of Perigal's dissection, and while he had seen other dissection proofs for Pythagoras' theorem before, none were as simple nor contained the symmetrical division of one square only. Glaisher remarked that Perigal had perhaps four or five other original dissections that he hoped to see published in up and coming issues of the Messenger. Only one other paper two years later ever appeared [123]. It was a dissection showing how a square could be converted into a rectangle of equal area with one of its sides given, perhaps not one of his best efforts. However, Perigal still had one more important dissection up his sleeve.

What is today regarded as Perigal's second most important geometric dissection is his six-piece trisection of the square. Here the problem is to dissever a single square into pieces that can be rearranged to form three smaller squares all identical in size. A nine-piece dissection was discovered as early as the tenth century by the Persian mathematician and astronomer Abū al-Wafā' who worked in Baghdad [57, pp. 31-32] but it was not minimal in terms of number of pieces. Perigal proposed the first sixpiece solution to the square trisection problem. Working in reverse he started with three equal smaller squares aligned in a row which when dissected into six pieces and rearranged formed a single larger square. His solution is believed to have been found around the same time as his more famous namesake dissection. The dissection Perigal found for the trisection of the square is shown in figure 6 .
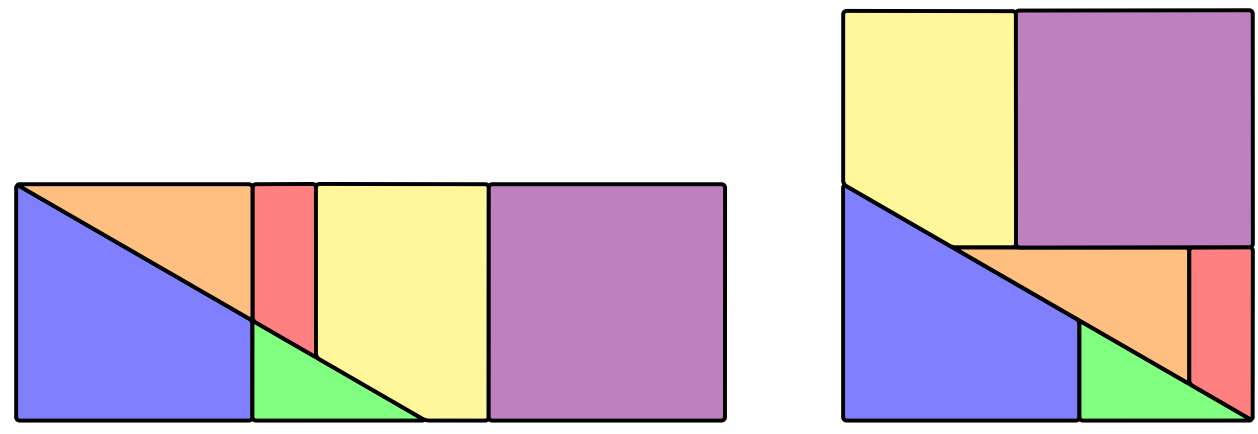

FiguRE 6. Perigal's six piece dissection for the square trisection problem.

In its construction it is very simple. Starting with the three smaller squares lined up in a row as shown in the left of figure 6, placing a compass at the top left corner of the square positioned on the left, extend it open to the top right corner of the middle square. Swinging it down to where it meets the base this point is then joined using a line to the top left corner of the square positioned on the left. Next, placing a compass on the bottom right corner of the square positioned on the right, extend it open to the bottom left corner of the middle square. Swing it up to where it intersects the top. A perpendicular from the top formed by the row of squares at this point is then dropped until it reaches the previous line just drawn. The row of three squares is now divided into six pieces which may be rearranged without rotation or reflection to form the larger square shown on the right of figure 6 . That the two figures are congruent in area can 
be proved using elementary trigonometry. Once again the beauty of this dissection lay in its simplicity, and at six pieces it is thought to be minimal.

A collection of fifteen dissections of Perigal's including his Pythagorean and his square trisection dissections finally appeared in a short booklet published in 1891 under the auspices of the Association for the Improvement of Geometrical Teaching (later renamed The Mathematical Association) [127]. It begins with an extract from his 1872 paper published in the Messenger. The fifteen dissection figures then follow without comment. The Association for the Improvement of Geometrical Teaching was founded in 1871 as a teachers' subject association concerned with developing alternative approaches to the standard treatment of geometry then taught in schools in Britain. Perigal's dissections not only fitted nicely within the association's remit but made available his work to a far wider audience beyond the world of learned academics and Perigal's immediate circle of friends. For teachers, methods showing how two unequal squares could be divided and reassembled so as to form a third larger square was undoubtedly the simplest and neatest ocular proof that could be used when introducing Pythagoras' theorem and it was not long before Perigal's dissection started appearing in elementary texts on geometry [78, pp. 93-94], [70, p. 93], [60, p. 189, Ex. 1022], [61, pp. 278-279].

Perigal's first paper on his most famous dissection, as already noted, appeared in the November 1872 issue of the Messenger. In an interesting twist, six months earlier his dissection had already appeared in print. Given by his good friend the English mathematician and astronomer Solomon Moses Drach (1815-1879) it can be found tucked away in the May 31 issue of the English Mechanic and World of Science, a popular weekly science magazine [50]. In response to a previous correspondent's supposedly new proof of Pythagoras' theorem Drach writes that his friend Perigal had many years ago given a truly new proof for this theorem using what he described as a 'mathematicomechanical' proof; namely a proof by geometric dissection. Sadly the beauty of Perigal's dissection is partially lost as the figure of the dissection accompanying the text is poorly drawn. Drach's account seems to have gone largely unnoticed.

An interesting question to ask is how widely known or how well-regarded by contemporaries were Perigal's two greatest scientific accomplishments - his dissection proof for Pythagoras' theorem and his six piece square trisection? If an obituary is a summation of one's life work listing all one's greatest achievements for posterity, then the answer would seem not very much. Of the fifteen obituaries I have managed to find for Perigal only one mentions his geometric dissection work. Fittingly, it is the one written for the London Mathematical Society [76].

Unknown to Perigal, and indeed to many for a long time after Perigal, is a striking resemblance between Perigal's dissection and one found in an anonymous Persian manuscript on ornamental geometry written around the turn of the fourteenth century. Entitled Fì tadākhul al-ashkāl al-mutashābiha aw al-mutawāfiqa (On similar and complementary interlocking figures), appearing in the bottom half of the page of folio $182 \mathrm{v}$ is a square interlocked with an irregular octagram [87]. This is shown in figure 7. It shows how a square can be transformed into an octagram. No text accompanies the figure, the text seen in the top left corner is for the figure that appears above it on the same page. Here the dissection uses eight pieces but it is obvious that if the smaller central square were not divided into four identical right-angled isosceles triangles one would have exactly Perigal's dissection.

As an enduring legacy of Perigal's dissection, in February of 1979 a US patent was awarded for the design of an apparatus to be used as a didactical aid in the teaching of Pythagoras' theorem that visually presented his celebrated dissection in mechanical form [137]. Here the device contained a knob that when turned varied the size of the acute angle in a right-angled triangle formed between its base and hypotenuse. In this 


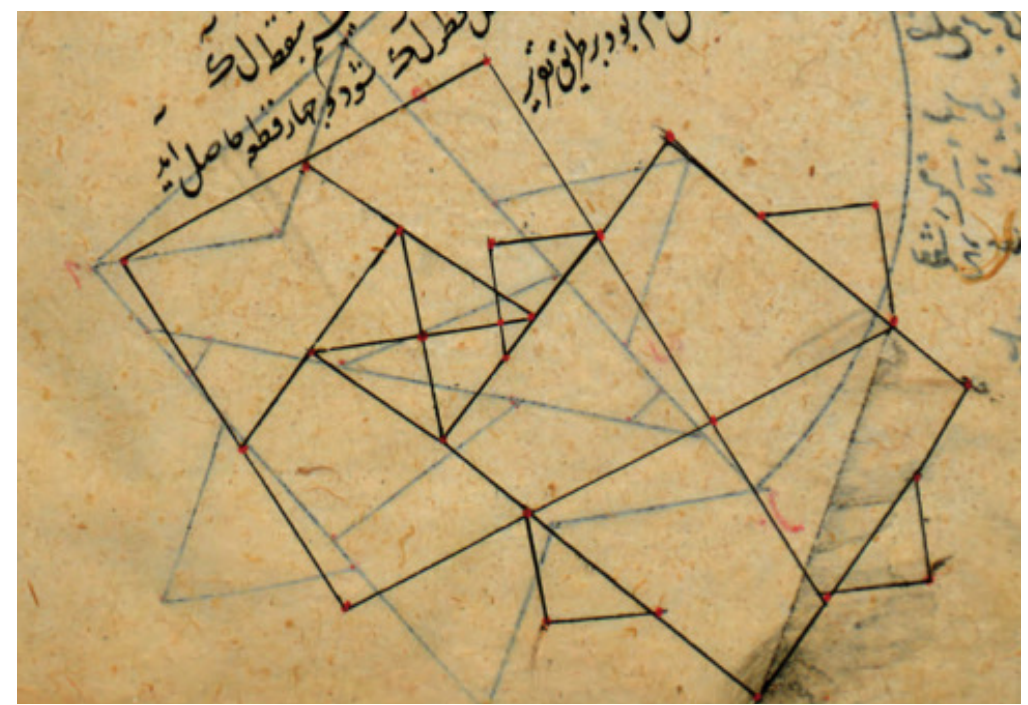

FiguRE 7. A striking dissection from a fourteenth century anonymous manuscript resembling Perigal's dissection. Image courtesy of Bibliothèque nationale de France.

way, from Perigal's dissection, the learner saw Pythagoras' theorem was true for all acute angles rather than just one particular case. It is not known if such a device was ever made. Of course nowadays such a demonstration can be readily achieved using a simple computer animation.

\section{The Moon controversy and Perigal the Paradoxer}

Perigal's view on the moon and his belief that it did not rotate on its own axis as it revolved about the earth is particularly curious. By the mid-1800s it was generally accepted by all within the scientific community that the fact that the moon always presented the same face when viewed from earth was the result of a compound circular motion. In this case it is a double motion which consists of a revolution of the moon around the earth combined with a rotation of the moon about its own axis. Perigal's unorthodox view on this matter led him to being labelled a 'paradoxer,' a neologism of de Morgan's. Between the years 1863 to 1866 a column called 'A Budget of Paradoxes' started appearing from time to time within the pages of The Athenceum, a weekly periodical published in London that covered a wide range of topics including literature, fine arts, music, theatre, politics, and popular science. Authored by de Morgan, this column focused on the exploits of people he called paradoxers. According to him a paradoxer was one who held views contrary to the generally excepted mainstream view. To de Morgan the term was not necessarily a pejorative term. It was only when the paradoxer was clearly wrong, or worst still - deluded - did they become what we would today call a crank.

Perigal's view on the motion of the moon remained unshaken throughout the course of his life. It led to him becoming embroiled in the so-called 'moon controversy' that periodically flared up throughout the course of the nineteenth century and saw him writing an ever-increasing number of pamphlets stating and defending his position. $\mathrm{He}$ also invented and built numerous mechanical models which he believed demonstrated his point regarding the non-rotation of the moon about its axis as it orbited round the earth. That the moon was thought not to rotate about its own axis relative to the fix stars was not new with Perigal. It was disputed on and off for at least decades before 
him. What seems to have led him down this path towards his final conviction was his extensive work with the lathe, and the geometric chuck in particular. Relying as it does for its operation on compound circular motion, the geometric chuck allowed Perigal to gain intimate familiarity with the workings of double and triple circular motions. As much as being a serious scientific tool for the investigation of complex, compound circular motion it unfortunately sustained his mistaken view.

Perigal seems to have fixed upon his ill-founded notion of a non-rotating moon sometime in the early 1840s. We find him first expressing his belief in one of his early private pamphlets he wrote dating from 1846-1849 [95]. For Perigal an orbiting moon rotating about its own axis ought to show all its sides to the earth, just as the earth, which clearly rotates, shows all its sides to the sun as it orbits about the latter. He also saw it as one of semantics stemming from the ambiguity between the terms rotation and revolution [98]. For Perigal, if rotation was movement of a body about its own axis and revolution was movement of a body round some exterior, usually distance, centre then revolution was an extension of rotation while rotation was a limit of revolution. In the Perigalian system of astronomy it was as if an invisible rod was attached between the earth and moon that was responsible for holding the face of the moon in its fixed position, preventing it from rotating about its own axis as it orbited round the earth.

The distribution of the two pamphlets Perigal had written outlining his views on the non-rotation of the moon was not very wide. Privately distributed, their small print runs ensured only close friends, acquaintances, and perhaps a few members of learned societies actually saw his work. And there they would have stayed, politely dismissed as a quaint idea from a man who busied himself with harmless eccentricities, destined to fade away as quickly as they came. Unfortunately this was not so. There were many others who shared Perigal's pet obsession with the moon. A few years later it burst forth into the most vociferous of public debates. Starting at the Philosophical Institution in Birmingham by one Jelinger C. Symons (1809-1860), who at the time was one of Her Majesty's permanent inspectors of schools [37], what began as a local discussion at one of the regular evening weekly meetings, so excited had the contest become it spilt over into the local papers before finally finding itself a few column inches of space in the hallowed pages of The Times of London. On Tuesday 8 April, 1856, a letter to the editor penned by Symons appeared in The Times under the heading 'The moon has no rotary motion' [158]. In the letter, Symons questioned why almost all school astronomy texts asserted the moon rotated about its own axis and suggested this was clearly not the case as for the moon to rotate all its sides ought to be visible from here on earth. A small glowing ember had just been dropped into a tinderbox. By the following day a full blown wildfire was raging out of control and would take years before finally exhausting itself.

The response was immediate. The following day The Times reported a vast postbag in reply to Symons' letter of which they chose to publish seven as a representative sample of all those received [166]. All were quick to impugn his non-rotatory thesis and admonished him for having the temerity to think it necessary to make his heterodox views a subject for The Times. Letters continued to tumble in at a rate of knots throughout the month of April. Symons doubled down and wrote again on April 14 still denying the rotation of the moon [159].

Symons' at times braggadocio tone had not helped either. It galvanised opposition against him and ensured the controversy continued to rumble on in the letters column of The Times until year's end when on December 13 Symons finally took leave from the debate by writing that he had decided not to take any further part in its discussion before concluding 'Common sense is with us already, and I dare say philosophers will come round to it in due time.' [160]. By this time, Symons had moved the debate 
to the pages of The English Journal of Education where he found a more sympathetic audience for his unconventional views. Here many of Symons' acolytes who had sent letters to The Times in support of him but failed in gaining publication, and others who had written to him directly supporting his view, found a ready outlet [167]. As the year wore on, and early into the following year, many letters in support for Symons' and a few against him appeared [68, 53, 168, 162, 85, 62, 156, 63].

By and large it appears Perigal was not one of Symons' public votaries as he himself did not take part in the unfolding controversy surrounding the moon debate of 1856 . If he did, at least no letter to either The Times or elsewhere appearing under his name is to be found. Perigal did however contribute as an appendix to a pamphlet Symons wrote on lunar motion [161] a mathematical proof of the type of curves he thought the moon ought to trace out in space if rotation about it own axis while orbiting round the earth were to occur [103]. By year's end Perigal had also written, at first a short than in more expanded form, pamphlet on the moon controversy [104, 105]. Here his main arguments for the moon's non-rotation covered the same ground as his earlier work. New material critiquing the work of many of those who had written to The Times admonishing Symons' non-rotatory view of the moon was also included. As Perigal saw it the central issue was what grounds were there for continuing to assert the moon rotated on its axis? As he writes, for him [105, p. 10]

The only grounds assigned are arbitrary definitions of rotation and revolution, which we say do not properly and strictly define either of them, and, moreover, are not definitions, but fallacious and untenable proportions.

The dispute was quickly narrowing down to one over the meaning of words. Wielding the semantic sword the intention seemed to be to confound common name motions for rotation and revolution as one and the same thing but which were really distinct from each other.

After 1856 things seemed to have settled down for a time until September 10, 1864, when de Morgan took aim at Perigal in his 'Budget of Paradoxes' column for The Athencum [48]. At issue were Perigal's three pamphlets [95, 98, 104]. Unlike many of the other paradoxers he had encountered, de Morgan saw Perigal differently. He commenced his column by informing his readers that twenty years earlier he had had the good fortune of working with Perigal who had produced for him most of the diagrams that were used in his article 'Trochoidal curves' that appeared in the Penny Cyclopadia [47]. These Perigal had cut directly from the lathe. These curves were produced using a so-called geometric chuck that for its operation relied on compound circular motion, a device we will have more to say about shortly. For a person who was intimately familiar with compound circular motion de Morgan thought Perigal should have known better. For the moon to permanently show only one of its faces as it orbits about the Earth was possible only if the rate of rotation of the moon about its axis exactly matches the rate of revolution round the Earth. Perigal referred to this 'assumption' as the 'Dogma of the Moon's Rotation' [110, p. 8] and believed it was based on a sophism he traced back to Galileo [110]. Despite this, de Morgan lets Perigal off lightly. The former clearly had respect for the latter and praises Perigal as being the most able amongst all the rotation deniers who had turned out with Symons.

Ironically de Morgan's gentle attack on Perigal may have been brought about by Perigal himself. In the January 1864 issue of The Astronomical Register Perigal writes that "A friend of ours has taken the trouble to versify "The Moon Controversy", [108]. Four octavo pages of the controversy in verse then followed under the name of 'Cyclops.' From the doctrines espoused and the turn of phase used, de Morgan suspected it was the work of Perigal, or at the very least, one of Perigal's very close 
supporters. Later we would learn it was Perigal himself, for Cyclops was a nickname of his given to him by a young girl who could not pronounce 'cycliod' correctly. Indeed, enchanted by his new name, Perigal later asked for it to be included on his tombstone (see section 8). Nor would it be the last time Perigal would commit his non-rotatory defence of the moon to verse. Further prose and poems of his defending the absence in rotation of the moon can be found in [72, p. 9], [27], [151].

The Astronomical Register was only in its second year of publication when Cyclops' poem appeared. The journal's remit was as 'a medium of communication for amateur observers, and all others interested in the science of astronomy.' As anodyne as Cyclops' poem may have seemed, by choosing to publish it the editors of the Register had unwittingly stepped into what would quickly become a maelstrom all of their own making. The Register was a monthly periodical. The following month, February, saw three letters responding to Cyclops poem and the moon controversy more generally [169]. To the first of these, by a certain 'Argus,' was reserved the most severe animadversion. As a taste of what was about to come, Argus opens with:

As you have permitted Mr. Perigal to bore us again with his crotchets about the moon, I trust you will allow me to ask him a simple question.

In March five more letters were published [170] including a reply from Cyclops [109]. By April it had become a full blown vexata quastio with the Editor pleading for mercy as a consequence of the enormous volume of letters received on the subject [171]. In the May issue fourteen letters appear, no doubt the tip of a very large iceberg [172]. At their conclusion the editor suggested "we should be glad to see the "Moon Controversy" drawing to a close' and reminded correspondents that the inappropriate tone that had been used in some of the letters received would no longer be tolerated. It was all to no avail. Letters continued to pour in, and be published, unabated every month until February the following year [173, 174, 175, 176, 177, 178, 179, 180, 181, 182]. An editorial change in policy announced in April 1865 to start in May to try and stem the flow saw 'communications not of general interest' would no longer appear as letters but would instead be inserted in pamphlet form as an appendix at the end of each issue at the personal expense of the author [182]. But still they came. Indeed the first to appear in appendix form was from Perigal himself. He sent two letters. The first was a reply to de Morgan's A Budget of Paradoxes column from the previous year [111]. The second was a repeat of an earlier attempt of his to eliminate what Perigal saw as an equivoque arising from the misuse of the terms rotation and revolution [112].

In the first letter, after republishing de Morgan's column in its entirety, Perigal's reply carefully took some of the former's criticisms and responded to them in verse. A particularly entertaining exchange comes from a line towards the end of Cyclops' poem concerning those that would have you believe the moon's rotation about its axis exists. It reads 'But still it totters proofless!' to which de Morgan responses by writing 'Proof requires a person who can give and a person who can receive,' only to have Perigal in his reply amusingly retort:

For proofs we need a giver and receivers;

For dogmas mere asserters and believers!

After May 1865 a few more letters appeared as appendices $[66,188,67,33]$ in the Register but the change in policy had its desired effect in stemming the flow of letters and brought the debate to a final close. And there it remained for the best part of three years before Perigal again revived it, this time with a simple ball and compass model he hoped would help clarify the difference between rotation and revolution[117]. Several more letters trickled in over the coming months [183, 1, 30, 31, 38, 39, 54, 59, 150, 184]. By late 1870 the debate was all but over [42], finally disappearing from the pages of the Register once and for all. 
Of course Perigal was not for turning. In the January 14, 1870 issue of English Mechanic and Mirror of Science a letter from Perigal appeared [118]. Renewing once more his emphatically held conviction of the impossibility of the moon rotating about its axis as it revolved round the earth he did so by again putting forth an incorrect model relying on the rigid connection between two bodies as one revolved round the other. The following week his error was pointed out by two correspondents. One of these letters was from the English astronomer and populariser of astronomy Richard Anthony Proctor (1837-1888) [130]. He wrote that there could not be too many occasions where he could recall the English Mechanic receiving a contribution from the august ranks of a Fellow of the Royal Astronomical Society and had heard a 'whisper' Perigal's views about rotation and revolution were a little heterodox. Writing rather tongue in cheek how pleased he was to find nothing to disagree with him in his letter the only point Proctor noticed was Perigal's letter seemed to have dropped a concluding paragraph. Some years later Proctor recalls asking Perigal if the absence of the moon turning on its axis supported a lunar heliocentric model of the universe [131, p. 179]. The latter admitted his objections to accepted views were by no means confined to the question of the moon's rotation and suggested the idea of a lunar heliocentric model was closer to the truth than many thought it to be. It seems Perigal was quite happy to hold more than one heretical view when it came to the moon.

Perigal continued to make diagrams and construct models that he hoped would convince others the moon did not rotate about its axis. Later in life it is said Perigal would try on many occasions to illustrate this fallacy using his walking stick as an experimental prop in the tea-room of the Royal Astronomical Society [28]. There was no hiding the fact Perigal held unorthodox views. When Perigal was described as a 'paradoxer pure and simple' [134] it was because the incorrect belief he clutched onto was widely known. As one anonymous writer observed, Perigal's idée fixe on the moon's lack of motion about its axis was '...familiar to everyone who was ever in his company.' [25, p. 480]. Because of this one may have thought he would have been persona non grata wherever he went, especially within astronomical circles. But surprisingly this was not the case and is a remarkable testament to his personal character. Almost unique among paradoxers he mixed and had long term friendships with some of Victorian England's leading scientific people. These included two Astronomer Royals; Sir George Biddell Airy (1801-1892) and Sir William Henry Mahoney Christie (18451922); the meteorologist, aeronaut, and astronomer James Glaisher (1809-1903), the physicist Silvanus Phillips Thompson (1851-1916), the three English mathematicians Arthur Cayley (1821-1895), Samuel Roberts (1827-1913), and Solomon Moses Drach (1815-1879), and the engineer and photographer Washington Teasdale (1830-1903). As he aged he was found to be a charming though somewhat eccentric old man who openly confessed his main astronomical aim in life was to convince others of their grave error in thinking the moon rotated on its axis, especially among the young whose views on the matter were the least firm [134]. Despite his sustained perseverance and avuncular manner it was all to no avail.

\section{The MOdel MAKer AND instrument Builder}

Throughout his life Perigal was a prolific maker of models and builder of various ingenious contrivances. Most of these were made to show the effects of compound circular motion or to demonstrate the truth of the lunarian paradox. Some were however very simple and demonstrated his famous geometric dissection or other geometric dissections he had devised [81, 82].

In March [5] and April [6] of 1846 and again in February [7] and March [8] of the following year Perigal had the opportunity of displaying several of his apparatuses at 
a number of soirées put on by Spencer Joshua Alwyne Compton (1790-1851), Second Marquess of Northampton, who at the time was the President of the Royal Society. One of these was what he termed a kinescope. It consisted of a bright steel ball attached to a system of multiplying wheels. For double circular motion, selecting various gear ratios between the two wheels, turning a handle rapidly saw light being reflected off the steel ball as it moved. Due to a persistence in vision the curve it traced out could be seen. One particular curve Perigal was fond of producing was what he called a 'retrogressive parabola.' It was retrogressive in the sense that the steel ball moved back and forth along a finite portion of a 'parabola' either side of its vertex. Indeed Perigal's kinescopes were the mechanical embodiment of what today are known as Lissajous figures, Perigal's work antedating that of Lissajous by a decade [77]. These figures are described by the set of parametric equations

$$
x(t)=a \sin (p t) \quad \text { and } \quad y(t)=b \sin (q t+\phi) .
$$

Here $a, b, p, q, t, \phi \in \mathbb{R}$. Physically, in terms of the moving steel ball found in Perigal's kinescope $x$ and $y$ give the position of the steel ball in the plane, $t$ is the time, $a$ and $b$ the amplitudes of oscillation, $p$ and $q$ the frequencies of the rotating gear wheels, and $\phi$ a phase shift that depends on the initial starting position used for the steel ball.

Lissajous figures are closed if and only if $q / p$ is rational. Perigal's retrogressive parabola can be obtained on setting $a=b$ such that $a \neq 0, p=1, q=2$, and $\phi=\frac{\pi}{2}$ in (1). Since $q / p=2$, not only will the resulting Lissajous figure be closed its Cartesian equation is given by

$$
y=\frac{a^{2}-2 x^{2}}{a}, \quad-a \leqslant x \leqslant a, a \neq 0,
$$

a parabola with vertex at $(0, a)$. Illustrations of two of Perigal's kinescopes are shown in figure 8 .

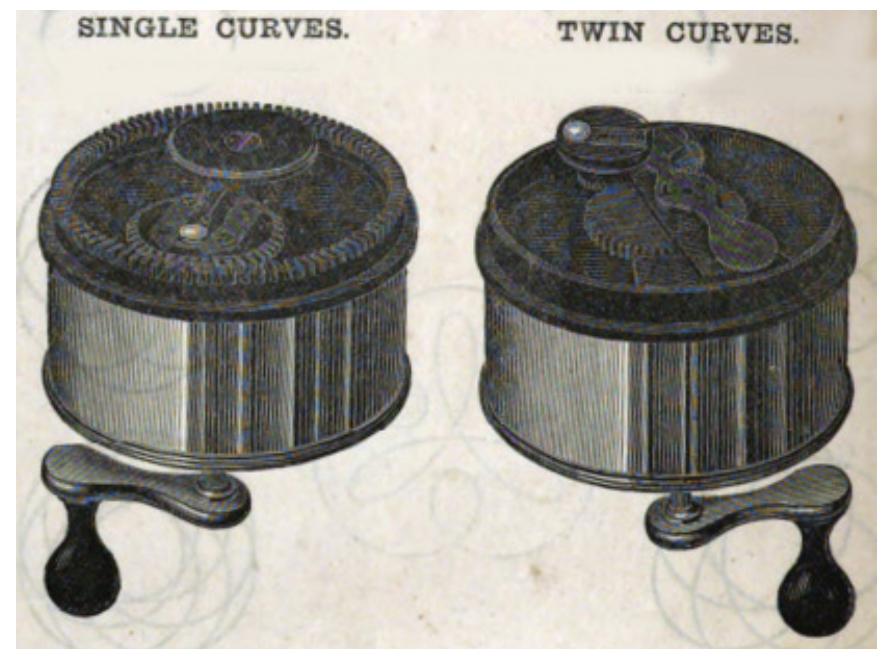

Figure 8. Two of Perigal's kinescopes that were made for sale [107]. These could be obtained from Messrs R. \& J. Beck, 31 Cornhill, London [126].

To these retrogressive curves Perigal supposed the paths followed by comets may be ascribed. While it was generally agreed comets followed either highly elongated elliptic orbits, thereby periodically returning, while others followed hyperbolic trajectories and were destine never to return, Perigal's retrogressive curves could model the former case. Being finite, they were closed, and were periodic as an object could regress back and forth along the curve. For Perigal a comet moving along one of his retrogressive 
parabolae allowed for a periodic return [4]. The parabolic shape was no problem either as the apparent path of an object moving along very elongated ellipses resembles very closely that of a parabola. One problem was that Perigal's proposal would have comets returning to us from opposite directions with each passing, something that was not explained and seems to have been overlooked by him.

Another model displayed by Perigal at the February 1847 soirée was a selenescope [7]. It consisted of three ivory balls as models for the moon such that one of three different movements could be imparted to each ball. For the first, it received a motion that caused it to rotate about its own axis and orbit round the earth with the same period and in the same direction. The second was the same as the first except the two motions were in opposite directions. For the third the moon revolved round the earth but did not rotate about its axis. For Perigal, this model confirmed to him the moon did not rotate about its own axis. These he continued to demonstrate for many years. At a soirée held by the President of the Royal Astronomical Society in June of 1864 we are told that, judging by the crowd which had gathered around Perigal's table, his various apparatuses showing the movement of the moon continued to generate much attention and excitement [9]. Still later in July 1876 under the title 'Mr Perigal's kinematic models,' we find in addition to his kinescopes and selenescope Perigal demonstrating various other of his models at the exhibition of scientific apparatus held in the galleries at South Kensington Museum [45]. These included what Perigal termed a 'soldier experiment,' a model designed to demonstrate the relative effects of rotation and revolution, a 'compass experiment' whereby a magnestised compass needle was shown to, and an unmagnetised compass needle was shown not to maintain its parallelism while revolving in a circle, and two gyroscopes that demonstrated the combined effects of revolution and of rotation, and of revolution only [45, pp. 71-72]. In all these models it is clear Perigal's intention was to convince interested visitors how preposterous the notion of a moon rotating on its axis was.

Shortly after appearing as part of the special loan collection of scientific apparatus at South Kensington Museum the model of his selenscope together with several other of his apparatuses were donated to the Royal Astronomical Society [65]. These donations were made on June 1879. In addition to his selenscope he also presented to the Society a lunarium which consisted of two clock dials rotating on a board and two other instruments he termed 'rotameters.' These, he writes, were to 'assist the Fellows of the Society in studying the resultant effects of double circular motion ... with particular reference to the movements of the earth, moon, and planets.' [65, p. 232]. One of these rotameters is shown in figure 9 .

In his ninetieth year in a programme for a Royal Society conversazione Perigal can still be found exhibiting one of his models [149]. Taking place on the evening of May 14, 1890, in the rooms at Burlington House the Royal Society's conversazione was one of the most important annual events on London's scientific calendar. As one of thirtyfour exhibits and exhibitors that evening we find Perigal hard at work demonstrating what in the programme is listed as a 'kinematic paradox.' Described as a remarkable result concerning double circular motion leads us to suspect it involved one of Perigal's rotameters, a model he remained convinced was an accurate description for the earthmoon system. Depending on double circular motion for its operation, when used as a model for the motion of the moon about the earth the apparent paradox, as Perigal saw it, was it did not produce the rotation the moon was supposed to have about its axis as it revolved round the earth.

Simpler models made and given away by Perigal were his card models used for demonstrating his famous geometric dissections. In fact, a model for his Pythagorean dissection and a nine part trisection of a square whose parts consisted of three different shapes 


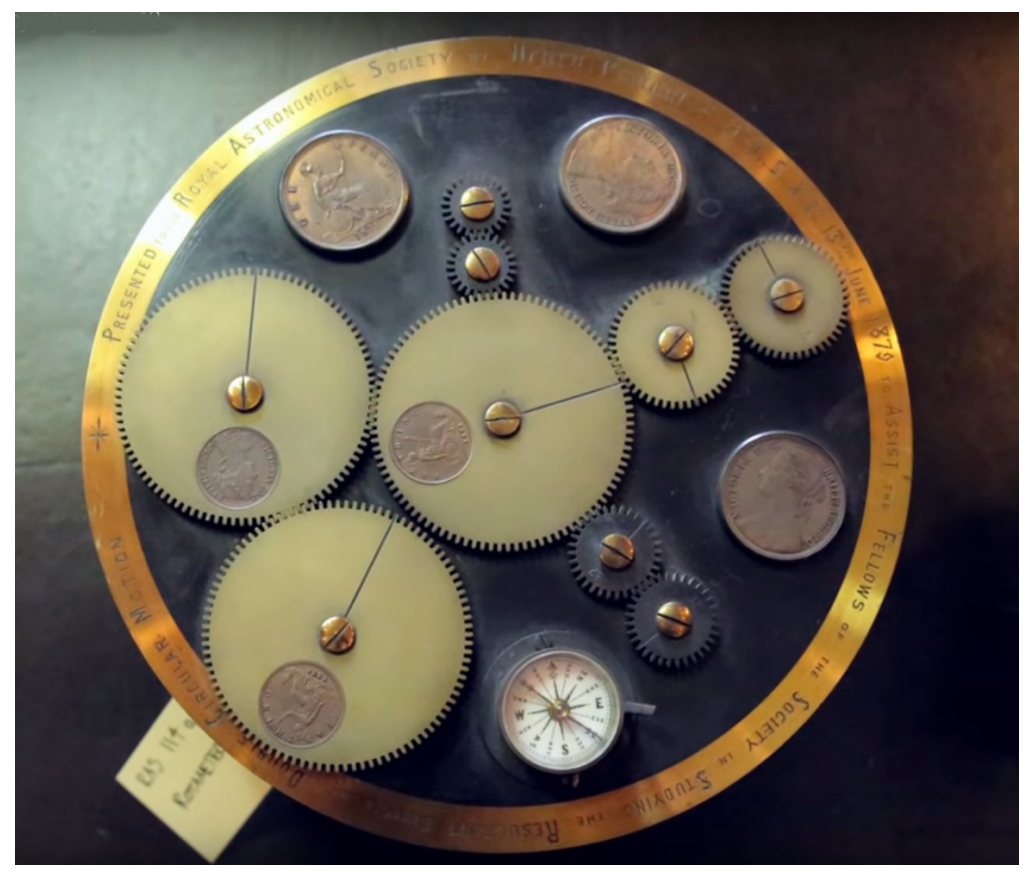

Figure 9. One of Perigal's rotameters. The inscription around the rim reads: Presented to the Royal Astronomical Society by Henry Perigal F.R.A.S \&c, \&c. 13th June 1879 to assist the Fellows of the Society in studying the resultant effects of double circular motion. Photograph courtesy of Brady Haran.

and sizes are known to have been exhibited by Perigal at the The Great Exhibition of the Works of Industry of All Nations of 1851, an international exhibition that took place in Hyde Park, London, between the months of May and October [52, pp. 314-315]. As late as 1904 Edward Mann Langley (1851-1933) writing in a review of a geometric text noted card models had once been produced by Perigal for the purpose of demonstrating his most famous dissection but did not know if they could still be obtained [71].

His indomitable belief concerning the moon's lack of rotation, while unfortunate, only added to the eccentric character of this curious natural philosopher. Writing shortly after his death an anonymous writer observed [24]

By the death of Mr. Henry Perigal ...the world loses one of its most scientific paradoxers. In season and out of season did he proclaim that the moon might, could, would, should, and did not rotate on her axis, and we have among our instruments at the Royal Astronomical Society a model constructed by him with that brilliant mechanical ability which was his leading characteristic, to enforce his hypothesis.

There is no doubt Perigal was an inventive builder of models and mechanical contraptions. Kinescopes, rotameters, selenescopes, lunarians, or gyroscopes - it was devices that involved compound circular motion to which he was principally drawn. All were built with a view to convincing others the moon did not rotate as it orbited the earth. Misguided belief, perhaps, but his failed attempts to convince others of his own nonrotatory belief left behind a rich collection of instruments that flowed from a creative mind. 


\section{ORnamental LATHE TURner AND COURBES MERVEILlEuse}

Perigal was a consummate ornamental lathe tuner. His tool of choice was what was then, and still is, known as the geometric chuck. Invented by John Holt Ibbetson in the early part of the nineteenth century the geometric chuck is a mechanism consisting of a number of geared wheels of various sizes on arbors that could move either in the same or opposite directions attached to two or more foundation plates called stages designed to produce two or more circular motions in parallel planes. When attached to the head of a lathe and cranked by hand turning a handle, the geometric chuck was capable of producing a myriad array of intricate curves and patterns etched either into wood or drawn onto paper by attaching a fixed stylus. All curves produced were the result of the superposition of circular motions.

Perigal's father was good friends with Ibbetson [43]. As a young man Perigal and Ibbsetson lived a few doors apart from each other in Smith Street, Chelsea, and this is perhaps how Perigal's interest in the geometric chuck was initially piqued. It was an expensive hobby to take up as the chuck alone was thought to have cost fifty guineas [56, pp. 68-69], a considerable sum of money at the time, and this was the principal reason why its use among ornamental turners was never great. It is most likely Perigal in the first instant benefited from the help and advice received from Ibbetson in the use of the geometric chuck. It would not be long before the apprentice began to outshine his master. An illustration depicting a geometric chuck from Perigal's day together with Perigal's own geometric chuck are shown in figure 10.
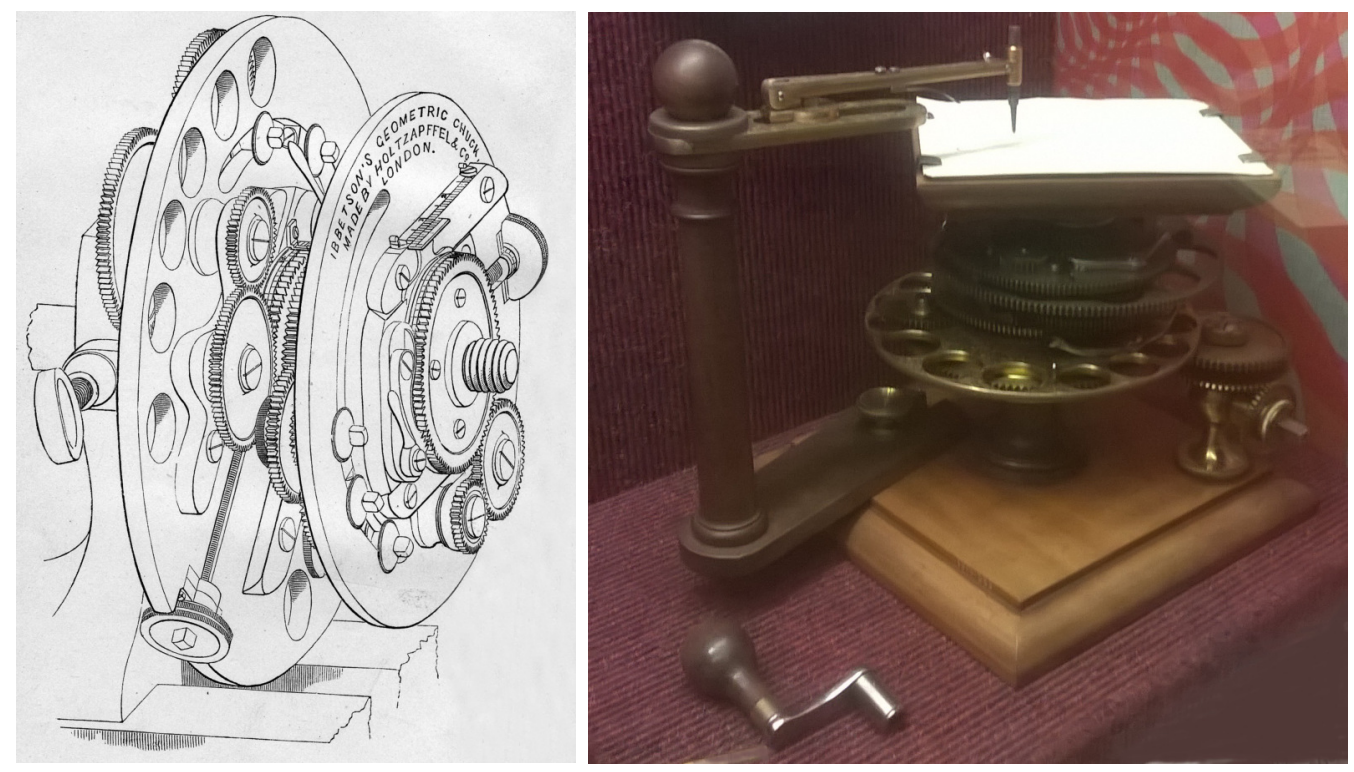

FiguRE 10. LEFT: An illustration of an Ibbetson geometric chuck that appeared as the frontispiece of Thomas Sebastian Bazley's Index to the Geometric Chuck of 1875 [34]. Right: The geometric chuck used by Perigal. It is laid in the horizontal position with a small sheet of paper mounted above one of the stages. It rotated beneath a fixed stylus as the lathe was slowly turned by hand. Photograph courtesy of Laurence Scales.

For most of the figures appearing in Perigal's published work the curves drawn are white on a black background. These were obtained from wooden blocks cut in the lathe with the geometric chuck, with the finished blocks used directly as stamps in the printing process. For additional cost the curves in the blocks could be cut to a sufficient 
depth to allow casts to be taken from them in type metal. Black curves on a white background could then be obtained.

Of all his contemporaries Perigal devoted the greatest amount of time to the study and classification of curves produced by the geometric chuck. While he recognised that the geometric chuck was well-suited to the purposes of ornamental turning, he later wrote that to him the greater value of the geometric chuck was as a means of investigating curves produced by compound circular motion [122]. Perigal did this by mainly confining his work to the purely mechanical where he produced and published, mostly privately, hundreds of curves $[92,96,97,101,106]$ though later on he did attempt to describe some of them mathematically $[106,108]$.

For Perigal his interest in curves of the type produced from compound circular motion was how they could 'exemplify and elucidate' the laws of motion [92]. As such, Perigal referred to the general class of curves of this type as 'kinematic' curves. We are told Perigal first traced out such curves geometrically by hand in 1835. It was not until 1840 that he was finally able to produce his kinematic curves mechanically by continuous circle motions using a geometric chuck $[11,125,35]$. For planets orbiting about the sun in nearly circular orbits the relative orbits for the different planets when seen from here on earth is the direct result of compound circular motion. Of the multitude of curves produced, Perigal's first aim was to identify those curves he thought could potentially account for the apparent motion of the planets. These he made and they can be found recorded in $[95,120]$.

The type of curves Perigal paid greatest attention to were those he termed bicircloids. These were a class of curves made up of two compound circular motions. These included well-known curves such as cycloids, epicycloids, hypocycloids, trochoids, epitrochoids, and hypotrochoids. Also included among these curves were the Lissajous figures, first developed by the American mathematician Nathaniel Bowditch (1773-1838) in relation to his study of two-dimensional motion of a pendulum when suspended from two points [41]. As already noted, Perigal was especially captivated by these figures. The Lissajous figure of the 'parabola' which he called the retrogressive parabola was a particular favourite [128]. Along with his dissection proof for Pythagoras' theorem he used it on his visiting cards (see figure 3 ) and would see to it eventually gracing one side of his tombstone (see figure 15). Though it is still not a widely used term today a bicircloid is defined as the locus of a point attached rigidly on a normal to the circumference of a circle rolling without slipping along a fixed circle [133, pp. 51-52]. A sample of some of Perigal's mechanically traced bicircloids produced using a geometric chuck are shown in figure 11.

Early on, Perigal is known to have sent copies of some of his mechanically drawn curves cut from the lathe using a geometric chuck to Sir John Frederick William Herschel (1792-1871) [46], the English polymath who at the time was widely regarded as the leading man of science in the kingdom. In a series of four letters dating from May 1839 until February 1840 Perigal sent to Herschel a selection of his curves together with an invitation to pay him a visit at his home in Chelsea to see how the curves were made. Though the offer does not appear to have been taken up by Herschel, in writing to a person of such statue it shows the importance Perigal placed in his work on kinematic curves.

Perigal took a keen interest in the types of terms used in describing the curves he drew. Initially he had called bicircloids spiroeids [92] but later switched this to bi-circloids [96, 97] before finally settling on bicircloids [101]. His sensibilities were occasionally rankled by terms in current usage such as the word eccentric, used to indicate circles not concentric with one another. To Perigal there was nothing 'odd' or 


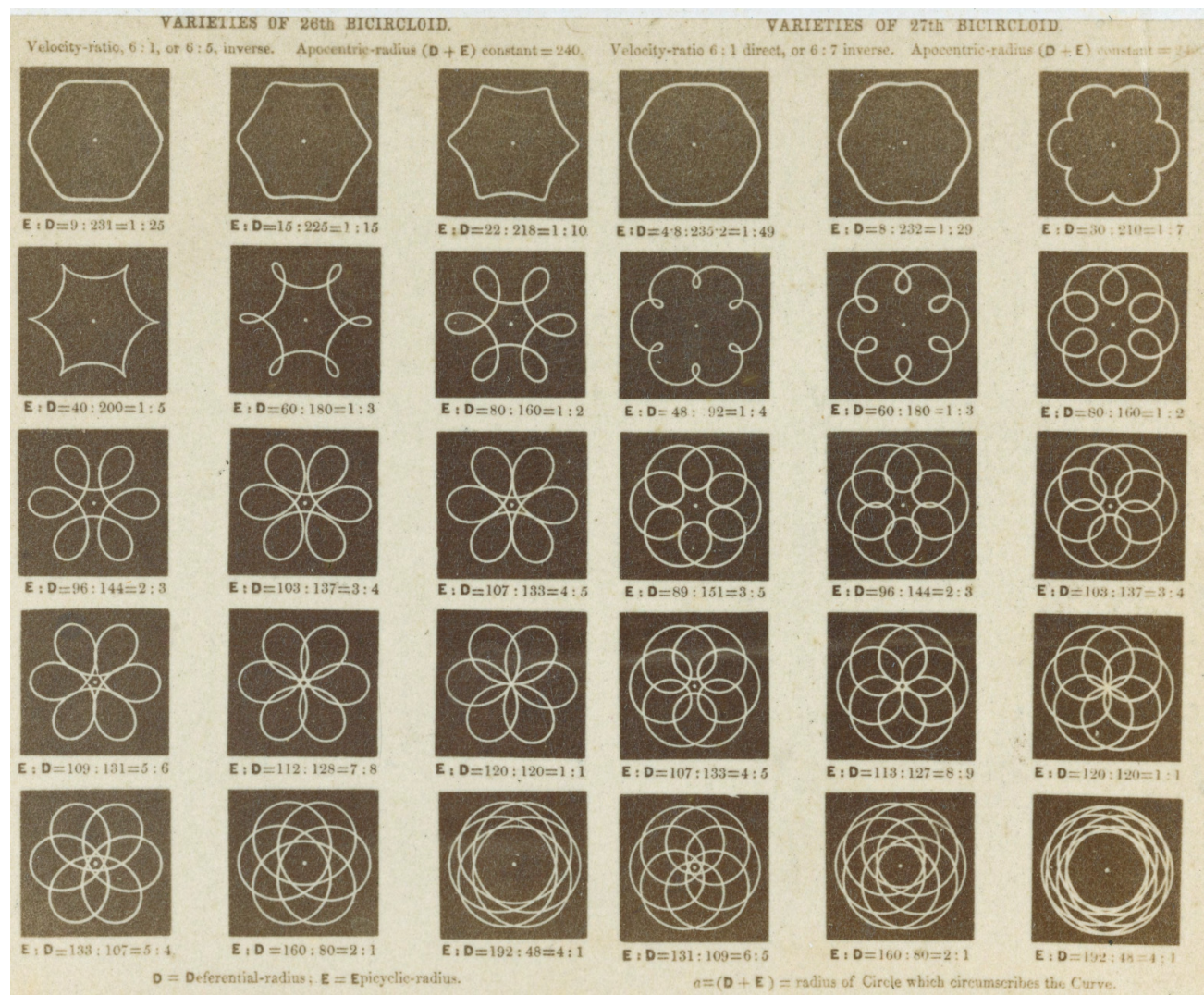

Figure 11. Example of a sheet of 'bicircloids' produced by Perigal. Photograph courtesy of Alexander Turnbull Library, Wellington, New Zealand (Ref: PA1-o-190-10).

'irregular' in a circle and he preferred the term ex-centric, meaning out of the centre, instead [119]. The term did not catch on.

It was of course the nature of the motion of the moon that was responsible for sustaining his interest in compound circular motion. He saw the bicircloids traced out from his lathe as an accurate description of the paths followed by heavenly bodies and it was just a matter of Perigal convincing his contemporaries of this truth. But in the end it was the faith he placed in his kinematic curves that ultimately led him astray in regard to the motion of the moon and other heavenly bodies. An interesting anecdote about the faith Perigal placed in the ability of the geometric chuck to act as an accurate description of the world around him comes to us from the Irish playwright George Bernard Shaw (1856-1950). He recalls [152, p. 12] that on a summer evening while standing on the pier at Broadstairs in Kent grazing up at the night sky an elderly gentleman from the Royal Astronomical Society came over and stood next to him. Seeing his sight was intently focused on the moon above, the elderly gentleman asked him how far off did he suppose the moon to be. Shaw professed that while he was not a scientific man he supposed perhaps it lay about forty miles away. Expecting to shock the gentleman by his answer as he knew the distance he had just quoted was somewhat less than the usual one, Shaw was surprise to discover how interested the elderly gentleman had become. Asked how he had arrived at his figure Shaw said he had made a guess based on looks. The excited elderly gentleman responded by saying he was a very good judge. Indeed, leaving fractions aside he confidently announced the distance to the moon was thirty-seven miles! He then proceeded to give Shaw a very elaborate and, 
at least to him, entirely convincing demonstration. He suggested that if astronomers cared to trace the actual orbit of the moon using a geometric chuck on a lathe as he had done, rather than basing their calculations of distance on the method of parallax, they would surely see the conclusion of thirty-seven miles to the distance of the moon was correct. The identification of the elderly gentleman from the Royal Astronomical Society who accosted Shaw on Broadstairs pier that evening as Perigal was not made by Shaw himself. Instead it was made the following year by an anonymous writer writing in The Observatory [26] and some years later by the American bibliographer Dan H. Laurence (1920-2008) [153, pp. 149-150], [154, pp. 213-214, 290], his comment on the geometric chuck having given away his identity. It seems Perigal the paradoxer was a lunar iconoclast in more ways than one.

Despite Perigal's shortcomings in his attempts to attach celestial significance to his kinematic curves, his skill and understanding in producing bicircloids from the geometric chuck was recognised among his peers. To help others understand how the generation of various different types of curves could be achieved he devised 39 rules in the use of the geometric chuck [86, pp. 276-280] and he was responsible for producing many figures used by others. For example his mathematician friend Solomon Moses Drach was in the habit of exhibiting collections of Perigal's various bicircloid drawings [74]. There was a time when his skillfully drawn curves had astonished everyone who saw them $[69$, p. 131]. By the late 1800s lantern slides were the cutting edge technology of their day. When Perigal's kinematic curves, in lantern slide form, were projected on a screen, a large audience found them a source of wonder when shown as part of a regular lecture Teasdale gave on scientific diagrams and the use of the lantern as an educational instrument [163, 164].

Perigal's curves also helped in embellishing the work of others. We have already seen how de Morgan was particularly grateful for the curves Perigal produced for the former's article 'trochoidal curves' that appeared in the Penny Cyclocedia [47]. The English astronomer Richard Anthony Proctor (1837-1888), in his Treatise on the Cycloid, after having seen de Morgan's article in the Penny Cyclocedia removed all the figures he had produced and replaced them with curves chiefly produced by Perigal [132]. And despite the curves of Perigal Proctor had included in his text he was only too willing to confide in his readers his fear of the inadequacy of the number chosen against the '... immense number, variety, and beauty of the sets of diagram published by Mr Perigal himself.' [132, p. xii]. Sadly not long after his death the valuable work of Perigal on his lathe was all but forgotten. One writer of a letter to the editor of the Philosophical Magazine urged some years later [64], that Perigal's method for drawing the ellipse or other Lissajous figures (see [100] and [102]) should be revived and recalled before being completely lost in the mist of time. This lone attempt was obviously unsuccessful as Perigal's work in this area is today largely unknown to most.

\section{Pyramids, Prizes, Cabinets of Curiosities, And tombstones}

As noted already, during his life it was rare for Perigal to communicate his work to the scientific community via publication in academic journals. One exception to this is found early on in his career where a paper on the possible method used in the construction of the pyramids appeared in The London, Edinburgh, and Dublin Philosophical Magazine and Journal of Science [94]. The paper was the product of a piece of work Perigal had offered for communication to the British Association for the Advancement of Science a few months earlier on a probable mode of raising very large weights such as the stones used in the construction of the pyramids.

As the ancient Egyptians had no advanced lifting machinery, the question of how stones of great size and weight could have been raised into place in the building of 
the pyramids had always vexed scholars. Herodotus tells us the great blocks of stone were moved over the ground on wooden rollers and raised up the steps along the sides of the pyramid using short planks of wood, but gives no further details as to how the actual lifting was achieved. Perigal's suggestion was rather simple and involved nothing beyond what was available to the Egyptians at the time of the construction of the Great Pyramid of Giza, which is thought to have been built somewhere around 2500 BCE. Finished stones were brought up to the base of the pyramid on wooden rollers. The rollers were then removed one by one until only the roller beneath the centre of the stone remained. This left the block of stone in a tipped position. Using thin planks of wood these were then used to build a fulcrum next to the remaining roller that was a little higher than it, while additional planks were placed underneath the raised end of the stone to a height below that of the fulcrum. A person walking along the top of the stone would then walk to the end of the stone where the planks underneath the stone had been placed, causing it to tip up. The last of the rollers could now be removed and a second fulcrum built up to a height just above that of the first while planks at a lower height compared to the fulcrum just constructed were built up under the section of the stone that had been lifted up. The person on top of the stone would now walk to the opposite end of the block causing it to rock back the other way. From here the process would be repeated until the stone was finally raised up to a height of the next step. It was then rolled off onto the step using wooden rollers placed underneath it. From here the stone would continue to journey up the side of the pyramid, being raised from step to step by repeating the process just described until it was finally placed in one of the courses of masonry. The sequence of diagrams shown in figure 12 depicts how the method proposed by Perigal was undertaken.
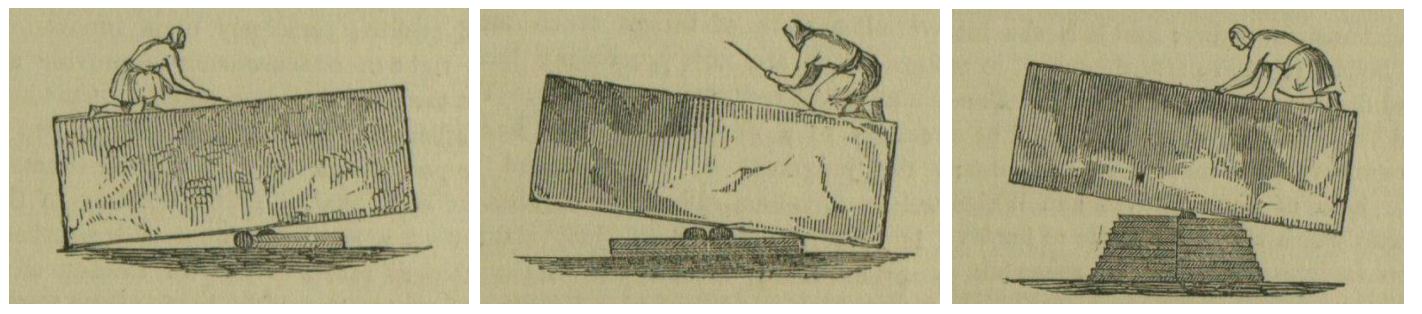

FiguRE 12. A sequence of diagrams depicting how the great stones of the pyramids could be raised using very simple technology based on a proposal first put forward by Perigal in 1844 at the fourteenth meeting of the British Association for the Advancement of Science [3].

The beauty in Perigal's proposal lay in its simplicity. As Perigal was fond of saying, it was as though 'the stone was made to raise itself by means of its own weight' [93]. Whether the method used by the ancient Egyptians in the construction of the pyramids was identical with the one put forward by Perigal is impossible to say.

The background story to Perigal's stone-raising paper is interesting. These are relayed to us in a series of three letters that prefaced his paper published in the Philosophical Magazine [94]. As mentioned already, in late 1844 Perigal had offered his paper for communication to the British Association at their up coming meeting to be held in York of that year. The paper was set to be delivered on September 27. For reasons that remain unclear, on September 18 Perigal had called upon the great English physicist Michael Faraday (1791-1867) to take charge of his paper. During the course of their discussions regarding how it could be possible to lift stone blocks of such great weight Faraday recalled a similar principle to the one being described by Perigal having been proposed some years earlier to lift heavy gunnery by one Lieutenant-Colonel Charles 
Cornwallis Dansey of the Royal Artillery, a decorated veteran of the battle of Waterloo. It had not occurred to Perigal that his proposed method for the raising of very large and heavy objects could have had applications to present day military purposes. By this stage Perigal had already had the explanatory diagrams that he intended to accompany his paper engraved, these having been made at some personal expense on his part (examples of these are shown in figure 12). Fearing allegations of plagiarism, Perigal wrote to Lieut-Col Dansey the following day outlining what he was planning to present to the British Association while at the same time enquiring if his probable mode of raising large objects had been anticipated by him. By reply post Dansey informed Perigal his proposed method had indeed been long practiced in the artillery drills. Dansey informed Perigal his proposed method had been partially used in the raising of a ship in dock and the technique had even been used to move Younger Memnon, a colossal ancient Egyptian statue made from granite, when installed onto a raised plinth in the British Museum in 1834. Despite all this Dansey felt the time and trouble Perigal had bestowed on the subject deserved to be better known by the general public beyond a small circle of artillerymen and encouraged him to proceed with his account.

All this was very fortunate. As Dansey suspected, learned men of science were unfamiliar with such a technique. It created considerable attention and excitement when first presented before the Mechanical Science section of the meeting. Usually these meetings were rather highbrowed and staid affairs. On this occasion it set tongues wagging. The following day it was reported in the local and London press [2,3]. Models based on his proposal were exhibited in the museum of the Royal Institution some years later [135], and the proposal even found a place in books of compilations containing popular accounts of science $[165,186]$.

Perigal's interest in kinematic curves has now been established. He continued to study and think about these curves deeply throughout his life. In early December of 1867 an interesting letter from Perigal first appeared in The Athencum, a week later in The Mechanics' Magazine, and a week after this in the English Mechanic and Mirror of Science [113, 114, 115]. Dated the 4th of November Perigal proceeds to tell us he had recently made a very interesting discovery concerning one of his kinematic curves and its intersection with a circle. What he found was a finite kinematic curve that cuts a circle in twelve places such that five of these points are equidistant from each other while the other remaining seven points were also equidistant from each other. The circle was thus divided into five equal arcs by the first set of points and seven equal arcs by the second set of points. Though the curve that satisfied this requirement was not new to Perigal he was not aware if such a 'singular' result was more generally known. Suspecting a general class of curves that divide a circle into equal number of arcs must be possible, so enamored had he become by this result he offered it as a challenge with a prize of $£ 5$, a not insignificant sum of money at the time, to any person who could demonstrate analytically, geometrically, or mechanically in a new and original manner the following. Find three plane curves that satisfy the following properties:

1. A finite curve that cuts a given circle at exactly five equidistant points.

2. A finite curve that cuts a given circle at exactly seven equidistant points.

3. A finite curve that cuts a given circle at exactly five equidistant points and at exactly seven equidistant points. The points of intersection between the two sets need not be all distinct.

4. Each curve must be continuous such that at the points of intersection with the circle the curve does not self-intersect itself nor is it cusped at all the points of intersection.

Solutions would be accepted up until the end of the year. Perigal referred to this problem as the 'polygonal sectioning of a circle' as joining adjacent points of intersection using 
a line segment a regular pentagon from the first curve will be formed while doing the same for the second curve gives a regular heptagon. In the third, one has a regular pentagon and heptagon which may or may not share a common point for one of their vertices. As Perigal was explicitly asking for finite curves to be found he clearly had his bicircloids in mind.

A week after the challenge was published in The Mechanics' Magazine, and exactly four days before year's end when the time to claim the prize would have expired, a solution by a certain R. B. appeared in the same magazine [29]. The curves Perigal sought are by no means unique. R. B. chose to give his or her solution for possible curves satisfying the stipulated conditions in polar form. Three curves in polar form $(r, \theta)$ similar to those given by R. B. that satisfy the four conditions given by Perigal are:

$$
\begin{aligned}
& \text { 1. } r=2+\sin \left(\frac{5 \theta}{2}\right) \text { and } r=1 \\
& \text { 2. } r=2+\sin \left(\frac{7 \theta}{2}\right) \text { and } r=1 \\
& \text { 3. } r=2+\sin \left(\frac{5 \theta}{2}\right) \sin \left(\frac{7 \theta}{2}\right) \text { and } r=2 .
\end{aligned}
$$

Plots of these curves are shown in figures 13 and 14 .
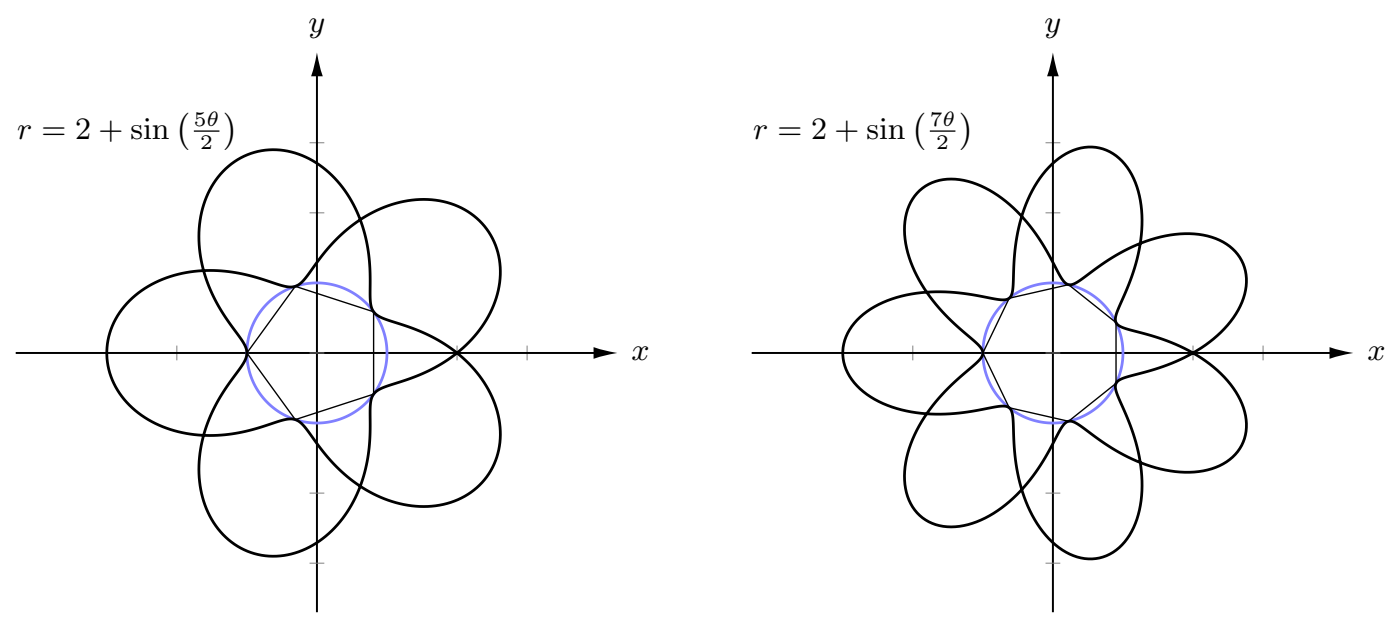

Figure 13. Plots of the first two curves that satisfy Perigal's conditions. The circles $r=1$ appear in blue. Inside each circle, on the left is drawn a regular pentagon while on the right is drawn a regular heptagon.

News the challenge had been accepted and the prize won was duly announced the following month $[32,116]$ though it appears the curves found by R. B. were not those initial sought by Perigal. What these curves were remains a mystery as Perigal does not tell us what they were. Indeed this was not the only time Perigal has left us wondering. A decade later saw Perigal communicate to the London Mathematical Society a paper entitled 'On a kinematic paradox,' [124] but nothing more is ever said about this paradox leaving one intrigued and left to ponder. The paradox we believe concerned the rotameter [10].

Later in his life Perigal's study at his home had become a private cabinet of curiosities [157]. As the place where all his work with the lathe was performed, where various instruments of his had been designed and built, and where everything connected to his scientific interests collected, the clutter of the room overflowed most of the space. A fortunate visitor to his home once observed [55, p. 25]: 

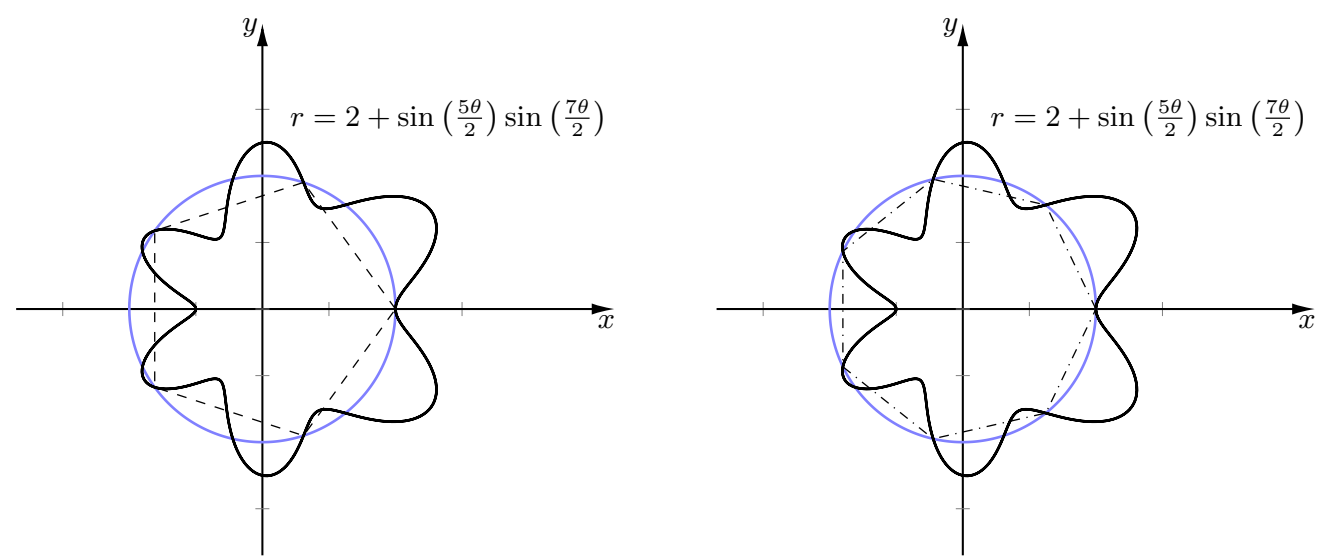

Figure 14. Plot of the third curve that satisfy Perigal's conditions. The circle $r=2$ appears in blue. Inside the circle, on the left is drawn a regular pentagon while on the right is drawn a regular heptagon.

What a scene it was, that labyrinth of strange relics of science, the marvels of bow-pen lacework, the instruments covered up to keep the dust off, the Philosopher's simple couch in the corner all in view of these quaint things, and the Philosopher himself indefatigably squaring the circle or trisecting an angle, or proving that the world is all wrong about the moon. I don't know what it was that he was at then, but it was all like a leaf out of a book, wonderful and almost incredible. And the birthday album laid there with the autographs of all the high priests of science. What has become of it I wonder, and of the bow-pen work, and all the odd things strewn about in such profusion? I must write an account of it some day. It was exquisite.

It must have been a magical place.

As in life, Perigal took his eccentric streak to the grave. The tombstone over his final resting place is noteworthy for the collection of his greatest deeds inscribed on it. The epitaph he left us points to what he considered to be his greatest scientific achievements. After being cremated at Woking in Surrey his ashes were interned in the churchyard of St. Mary and St. Peter Church in Wennington that was then located in Essex but is now part of Greater London (the London Borough of Haverin). Over his ashes was erected a square column tombstone of approximately 1.5 metres in height. On the front face is a very long inscription which reads:

\author{
(on column) \\ SACRED TO THE MEMORY OF \\ HENRY PERIGAL \\ ( CYCLOPS ) \\ F.R.A.S. F.R.M.S. M.R.I. \\ 40 YEARS TREASURER OF R. MET. S. \&C \\ BORN 1ST APRIL 1801. \\ DIED 6TH JUNE 1898. \\ CREMATED AT WOKING \\ HIS ASHES LIE BENEATH \\ DESCENDED FROM A HUGUENOT FAMILY \\ WHO ESCAPED FROM FRANCE TO ENGLAND \\ AFTER THE REVOCATION OF THE \\ EDICT OF NANTES IN 1688.
}




\author{
(on upper plinth) \\ A LEARNED AND INGENIOUS GEOMETRICIAN \\ HE INVESTIGATED AND ILLUSTRATED \\ THE LAWS OF \\ COMPOUND CIRCULAR MOTION. \\ (on lower plinth) \\ GREATLY BELOVED AND HIGHLY ESTEEMED \\ BY A LARGE CIRCLE OF RELATIVES AND FRIENDS. \\ "WHEN I CONSIDER THY HEAVENS THE WORK OF \\ THY FINGERS, THE MOON AND THE STARS WHICH THOU \\ HAST ORDAINED, WHAT IS MAN THAT THOU ART \\ MINDFUL OF HIM?" $\quad$ PS. VIII., 3. 4.
}

The inscription appearing on the lower plinth, except for the last three letters of the first line, is now lost. An inscription also appears at the back. Containing a single quotation located on the central column, it reads:

\title{
"ONE OF THOSE UNWELCOME \\ PREACHERS WHO THANKLESSLY \\ RETEACH THEIR TEACHERS."
}

A decade after it was erected it was asked in Notes and Queries, a periodical devoted to reader questions, if the source of the quotation was known [83]. It was not, and therefore appears to be one of Perigal's own. It seems to me Perigal saw himself as the 'unwelcomed preacher,' preaching the moon did not rotate about its axis, who tirelessly tried to 'reteach his teachers,' namely all and sundry, of such a fallacy. A photograph of the tombstone as it appeared shortly after it was erected is shown in figure 15 to the left, and as it did in 2006 to the right. As can be seen the initial black engraving used for the lettering and diagrams has all but disappeared.
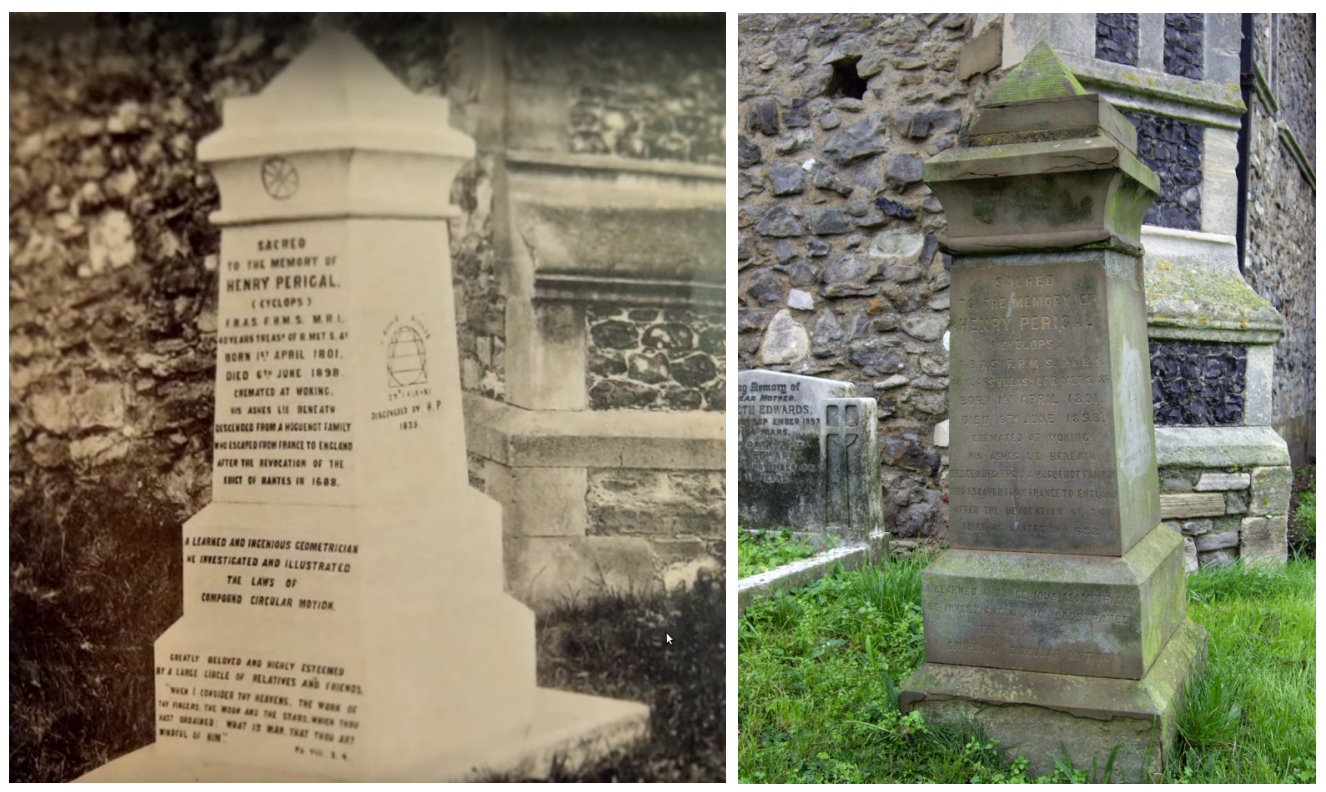

Figure 15. Left: Perigal's tombstone as it looked shortly after his death. The figure seen on the right side is that of his 'retrogressive parabola.' His more famous Pythagorean dissection appears out of view to the left. Photograph taken from [89]. Right: As his tombstone appeared in 2006. Photograph courtesy of John Attfield. 
More interesting are the inscriptions that appear on either side of the main inscription of the tombstone. On the south side is Perigal's retrogressive parabola. It is the diagram that can be seen on the right side of the figure shown on the left. The inscription below the diagram reads: DISCOVERED BY H. P. / 1835. On the north side appears a diagram showing his now celebrated dissection proof for Pythagoras' theorem. Below the diagram the inscription reads: DISCOVERED BY H. P. / 1830. Today each of these depictions are barely visible, having lost their original black outlining. A photograph together with a retracing showing how Perigal's dissection appears more recently can be seen in [43]. It is a fascinating self-styled tribute left behind by a man who thought the value of his work often went unappreciated by his peers.

\section{Conclusion}

Henry Perigal - amateur mathematician, pamphleteerist, master ornamental lathe turner, doyen of London's scientific establishment who dabbled in astronomy, meteorology, microscopy, and photography. A man whose contributions lay at the periphery of scientific concerns throughout the mid to late nineteenth century, he was nonetheless destined to be remembered for the dissection that now bears his name. Highly regarded and held with affectionate esteem Perigal was welcomed wherever he went. Moving and interacting within the highest circles of Victorian England's scientific establishment it was all the more curious to see Perigal labelled a paradoxer during his own life. Mulishly staunch in his view on the moon's lack of rotation, that was the quiddity of Perigal. History has bequeathed to us an intriguing, peculiar, and at times exasperating character who today deserves to be better known. We have told the story of this respected amateur, and in doing so, hope to have lifted him out of obscurity.

\section{ACKNOWLEDGEMENTS}

The author is grateful to Lance Putnam for providing copies of the two Perigal documents [92] and [101]. Permission from Brady Haran, Laurence Scales, and John Attfield for the photographs used in Figures 9, 10, and 15 are gratefully acknowledged.

\section{REFERENCES}

[1] A Looker-On: Rotation and revolution, The Astronomical Register (7) 81 (1869), 204-205.

[2] Anonymous: Yorkshire Gazette, 28 September 1844, p. 8.

[3] Anonymous: British Association for the Advancement of Science, The Illustrated London News, September 28, 1844, p. 197.

[4] Anonymous: New law of compound motion, The Civil Engineer and Architect's Journal, Scientific and Railway Gazette (9) May (1846), 156.

[5] Anonymous: New law of compound motion, The Literary Gazette, and Journal of the Belles Lettres, Arts, Sciences, \&c, No. 1523 (28 March 1846), 289.

[6] Anonymous: The Marquis of Northampton's soirée, The Literary Gazette, and Journal of the Belles Lettres, Arts, Sciences, \&c, No. 1525 (11 April 1846), 339-340.

[7] Anonymous: Marquis of Northampton's soirée, The Literary Gazette, and Journal of the Belles Lettres, Arts, Sciences, \&c, No. 1570 (20 February 1847), 151.

[8] Anonymous: Marquis of Northampton's soirée, The Literary Gazette, and Journal of the Belles Lettres, Arts, Sciences, \&c, No. 1574 (20 March 1847), 236.

[9] Anonymous: Royal Astronomical Society - The President's soirée, The Astronomical Register (2) 19 (1864), 149-150.

[10] Anonymous: Mathematical Society, Nature (19) 478 (1878), 162.

[11] Anonymous: Solomon Moses Drach, Monthly Notices of the Royal Astronomical Society (40) 4 (1880), 191-192.

[12] Anonymous: Notes, The Observatory, A Monthly Review of Astronomy (14) 178 (1891), 291-292.

[13] Anonymous: News, The Journal of the Camera Club (7) 84 (1893), 138.

[14] Anonymous: Obituary Notice - Henry Perigal, The Times (London), June 9, 1898, p. 6.

[15] Anonymous: Obituary Notice - Henry Perigal, Morning Post, June 9, 1898, p. 8. 
[16] Anonymous: Obituary Notice - Henry Perigal, Nature (58) 1493 (1898), 131.

[17] Anonymous: Obituary Notice - Henry Perigal, English Mechanic and World of Science (67) 1733 (1898), 378.

[18] Anonymous: A long-lived family, Bury and Norwich Post, June 14, 1898, p. 2.

[19] Anonymous: Obituary Notice - Henry Perigal, Science (7) 182 (1898), 858.

[20] Anonymous: Obituary Notice - Henry Perigal, The Observatory, A Monthly Review of Astronomy (21) 268 (1898), 282-283

[21] Anonymous: Obituary Notice - Henry Perigal, The British Journal of Photography (45) 1989 (1898), 397.

[22] Anonymous: In memoriam - Henry Perigal, Science-Gossip (5) 50 (1898), 59.

[23] Anonymous: Obituary Notice - Henry Perigal, The Photogram (5) 55 (1898), 233-234.

[24] Anonymous: The Late Mr. Henry Perigal, English Mechanic and World of Science (67) 1736 (1898), 449.

[25] Anonymous: The progress of astronomy in 1898, English Mechanic and World of Science (68) 1763 (1899), 479-481.

[26] Anonymous: From an Oxford note-book, The Observatory, A Monthly Review of Astronomy (24) 306 (1901), 253-255.

[27] Anonymous: Notes, The Observatory, A Monthly Review of Astronomy, (27) 344 (1904), 217.

[28] British Astronomical Society: Obituary Notice - Henry Perigal, Journal of the British Astronomical Association, (8) 9 (1898), 382-383.

[29] R. B.: Polygonal sections, etc, The Mechanics' Magazine (87) December 27 (1867), 424.

[30] G. P. B.: Rotation, The Astronomical Register (7) 80 (1869), 172.

[31] T. W. Backhouse: The moon's rotation, The Astronomical Register (7) 77 (1869), 177-178.

[32] E. F. Baker: Polygonal sections of the circle, English Mechanic and Mirror of Science (6) 145 (1868), 333

[33] T. P. Barkas: Rotation of the earth and moon, The Astronomical Register (4) 40 (1866), 126-127.

[34] T. S. Bazley: Index to the geometric chuck: A treatise upon the description, in the lathe, of simple and compound epitrochoidal or "geometric" curves, Waterlow and Sons, London, 1875.

[35] C. E. Benham: The graphic representation of harmongraph curves, Knowledge and Scientific News. A Monthly Journal of Science (New Series), (6) 7 (1909), 269-270.

[36] R. Bentley: The growth of instrumental meteorology, Q. J. R. Meteorol. Soc. (31) 135 (1905), 174-192.

[37] F. Bird: The moon controversy, The Astronomical Register (2) 24 (1864), 297.

[38] F. Bird: The non-rotation theory, The Astronomical Register (7) 78 (1869), 140-141.

[39] W. R. Birt: The moon's rotation, The Astronomical Register (7) 80 (1869), 172.

[40] F. Boase: Entry under PERIGAL, HenRy Modern English biography containing many thousand concise memoirs of persons who have died between the years 1851-1900 with an index of the most interesting matter, Volume 6, Netherton and Worth, London, 1921.

[41] N. Bowditch: On the motion of a pendulum suspended from two points, Memoirs of the American Academy of Arts and Sciences (3) 2 (1815), 413-436.

[42] D. C. The moon's motion, The Astronomical Register (8) 92 (1870), 180.

[43] B. Casselman: On the dissecting table: Henry Perigal 1801-1898, Plus Maths, Issue 16, 2001. https://plus.maths.org/content/dissecting-table (accessed 02-07-2020)

[44] E. Collignon: Pythagoras's theorem, Proc. Edinb. Math. Soc. (25) (1906), 91-94.

[45] Science and Art Department of the Committee of Council of Education: Catalogue of the special loan collection of scientific apparatus at the South Kensington Museum, George E. Eyre and William Spottiswoode, London, 1876.

[46] M. J. Crowe, D. R. Dyck, J. J. Kevin (editors): Calendar of the correspondence of Sir John Herschel, Cambridge University Press, Cambridge, 1998.

[47] A. de Morgan: 'Trochoidal curves,' in The Penny Cyclopadia of the Society for the Diffusion of Useful Knowledge, Volume 25, Charles Knight and Co., London, 1843, pp. 282-290.

[48] A. de Morgan: A budget of paradoxes. (No. XIX. 1849-1850.), The Athenæum, No. 1924 (1864), 340. Reprinted in: A. de Morgan: A Budget of Paradoxes, Longmans, Green, and Co., London, 1872 , pp. 261-262.

[49] S. M. Drach: An easy rule for formulizing all epicyclical curves with one moving circle by the binomial theorem, Phil. Mag., Series 3, (34) 231 (1849), 444-448.

[50] S. M. Drach: New (?) proof of Pythagoras' theorem, English Mechanic and World of Science (15) 375 (1872), 282.

[51] E. B. Elliott: Some secondary needs and opportunities of English mathematicians, Proc. Lond. Math. Soc. (30) 658 (1898), 5-23. 
[52] R. Ellis (editor): Exhibition of the Works of Industry of All Nations, 1851. Reports by the Juries on the subjects in the thirty classes into which the exhibition was divided, William Clowes and Sons, London, 1852.

[53] A. J. Ellis: Lunar rotation, The English Journal of Education (10) 115 (1856), 324-332.

[54] A. Elvins: The Moon: Its motion and physical constitution examined, The Astronomical Register (7) 84 (1869), 260-264.

[55] A. Filippoupoliti: 'What a scene it was, that labyrinth of strange relics of science': Attitudes towards collecting and circulating scientific instruments in nineteenth-century England, Cultural Studies (2) 1 (2013), 16-37.

[56] R. J. Farrants: The President's address for the year 1862, Transactions of the Microscopical Society of London (9) (1862), 59-76.

[57] G. N. Frederickson: Dissections: Plane and fancy, Cambridge University Press, Cambridge, 1997.

[58] G. N. Frederickson: Hinged dissections swinging and twisting, Cambridge University Press, Cambridge, 2002.

[59] W. B. Gibbs: Motion of the moon, The Astronomical Register (7) 75 (1869), 67.

[60] C. Godfrey and A. W. Siddons: Elementary geometry. Practical and theoretical, Cambridge University Press, Cambridge, 1903.

[61] C. Godfrey and A. W. Siddons: The teaching of elementary mathematics, Cambridge University Press, Cambridge, 1931.

[62] S. A. Good: The moon's motion, The English Journal of Education (11) 121 (1857), 31.

[63] S. A. Good: The moon does not rotate on her own axis, The English Journal of Education (11) 125 (1857), 155.

[64] G. Greenhill: [Letter to the Editor], Phil. Mag., Series 6, (35) 205 (1918), 140.

[65] H. D. Howse: The Royal Astronomical Society instrument collection: 1827-1985, Q. J. R. Astron. Soc. (27) 2 (1986), 212-236.

[66] E. J.: The moon controversy, The Astronomical Register (3) 29 (1865), Appendix, 1-3.

[67] E. J.: The moon controversy, The Astronomical Register (3) 35 (1865), Appendix, 1-6.

[68] T. Kentish: Proofs of the moon's rotation, The English Journal of Education (10) 114 (1856), $275-277$.

[69] R. Kerr: Hidden beauties of nature, The Religious Tract Society, London, 1895.

[70] E. M. Langley and W. S. Phillips: The Harpur Euclid: An edition of Euclid's Elements, revised in accordance with the reports of the Cambridge Board of Mathematical Studies, and the Oxford Board of the Faculty of Natural Science, Longmans, Green, and Co., London, 1894.

[71] E. M. Langley: Review of Geometric theorems practically demonstrated by means of dissected models. By Thorold Gosset. (G. Philip and Son. 4s.), School: A Monthly Record of Educational Thought and Progress (2) 9 (1904), 116.

[72] H. Lee: President's address, First Report and Abstract of Proceedings of the Croydon Microscopical Club, 1871, 7-14.

[73] F. Lindemann: Über die Zahl $\pi$, Math. Ann. (20) 2 (1882), 213-225.

[74] London Mathematical Society: Proceedings, Proc. Lond. Math. Soc. (9) 129 (1878), 75.

[75] London Mathematical Society: Proceedings, Proc. Lond. Math. Soc. (25) 494 (1894), 305.

[76] London Mathematical Society: Obituary Notice - Henry Perigal, Proc. Lond. Math. Soc. (29) 657 (1898), 732-735.

[77] J. Lovering: Anticipation of the Lissajous curves, Proceedings of the American Academy of Arts and Sciences (16) (1881), 292-298.

[78] J. S. Mackay: The Elements of Euclid. Books I to VI with deductions, appendices, and historical notes, W. \& R. Chambers, London, 1884.

[79] P. A. MacMahon: Pythagoras' theorem as a repeated pattern, Nature (109) 2737 (1922), 479.

[80] F. P. Mahlo: Topologische Untersuchungen über Zerlegung in ebene und sphaerische Polygone, $\mathrm{PhD}$ thesis, Vereinigte Friedrichs-Universität in Halle-Wittenberg, Halle, 1908.

[81] M. McCartney: Perigal artefacts, London Mathematical Society Newsletter, No. 450, September (2015), 25.

[82] M. McCartney: Perigal artefacts, London Mathematical Society Newsletter, No. 484, September (2019), 13.

[83] Mediculus: Is the author known?, Notes and Queries: A Medium of Intercommunication for Literary Men, General Readers, etc. [Series 10] (12) 294 (1909), 128.

[84] H. R. Mill: Meteorological memories, Q. J. R. Meteorol. Soc. (67) 292 (1941), 315-326.

[85] D. Mushet: The mathematicians, The English Journal of Education (10) 118 (1856), 435-437.

[86] W. H. Northcott: A treatise on lathes and turning, simple, mechanical, and ornamental, Longmans, Green, and Co., London, 1868. 
[87] A. Özdural: English translation of On similar and complementary interlocking figures in The arts of ornamental geometry, G. Necipoğlu (editor), Brill, Leiden, 2017, pp. 179-334.

[88] F. Perigal: Some account of the Perigal family, Harrison and Sons, London, 1887.

[89] F. Perigal: Henry Perigal. A short record of his life and works: Extracts from his diaries, and reprints of occasional notices and obituaries from scientific and other publications, accompanied with illustrations of specimens of a few of his designs, both by the bow-pen and lathe, Bowles and Sons, London, 1901.

[90] H. Perigal: Bow-pen drawings, 1832, 91 drawings.

[91] H. Perigal: Geometric dissections and transformations: Affording ocular demonstrations of geometrical theorems by the dissection of the figures and the transposition of the component parts, London, 1835, 12 pp.

[92] H. Perigal: Experimental researches in kinematics; designed to exemplify and elucidate the laws of motion, by the organical development of their representative, or characteristic curves, the resultants of combinations or movements, London, 1838-1842.

[93] H. Perigal: On the probable mode of constructing the pyramids, Report of the Fourteenth Meeting of the British Association for the Advancement of Science, John Murray, London, 1845, pp. 103-104.

[94] H. Perigal: On the probable mode of constructing the pyramids; introduced by letters relating to the history of the subject, addressed to Lieut.-Col. Sabine, Lieut.-Col. Dansey, and the Author, Phil. Mag., Series 3, (25) 168 (1844), 404-412.

[95] H. Perigal: Notes on the kinematics effects of revolution and rotation, with reference to the motions of the Moon, and of the Earth, which are assumed in the present system of astronomy, London, 1846-1849, $48 \mathrm{pp}$.

[96] H. Perigal: Kinematic bi-circloids; parabolites, 1846-1849. Sheets of diagrams.

[97] H. Perigal: Contributions to kinematics. Classification of bi-circloids, curves of two curvatures (in the same plane), the resultants of two circular movements, 1849, Chelsea, 8 pp.

[98] H. Perigal: On the misuse of technical terms. Ambiguity of the terms rotation and revolution, Chelsea, 1849, 16 pp.

[99] H. Perigal: Effects of compound circular motion, London, 1851, 8 pp.

[100] H. Perigal: Geometric maps exhibiting the method of delineating curves through the intersections of trigonometric lines, Chelsea, 1853, 8 pp.

[101] H. Perigal: Perigal's contributions to kinematics. Bicircloids, Chelsea, 1854, 6 sheets.

[102] H. Perigal: Ellipses, 1855, 16 pp.

[103] H. Perigal: Proof of the curves that would be described by any point in the Moon, if she rotated on her own axis, in the same time that she revolves round her orbit in Lunar motion. The whole argument stated, and illustrated by diagrams; with letters from the Astronomer Royal and others, Groombridge and Sons, London, 1856, pp. 24-25.

[104] H. Perigal: The Moon controversy. Facts v. definitions, London, 1856, 4 pp.

[105] H. Perigal: The Moon controversy. Facts v. definitions, London, 1856, 16 pp.

[106] H. Perigal: Perigal's contribution to kinematics. Transformation of kinematic bicircloids, curves of two curvatures (in the same plane), the resultants of two circular movements: exhibiting the varieties of the curve (called its phase) dependent upon the proportion of the variable element, the radial-ratio; the other elements, the velocity-ratio and the direction of motion, being constant, 1859 .

[107] H. Perigal: Kinescope, 1860, 2 pp.

[108] H. Perigal (as Cyclops): Revolution and rotation, The Astronomical Register (2) Supplement (1864), 1-8.

[109] H. Perigal (as Cyclops): The moon controversy [Letter to the Editor], The Astronomical Register (2) 15 (1864), 64.

[110] H. Perigal: The moon controversy, 1864, $10 \mathrm{pp}$.

[111] H. Perigal: A budget of paradoxes - A reply, The Astronomical Register (3) 29 (1865), A4-A5.

[112] H. Perigal: On the phenomena arising from the diurnal rotation of the Earth on its own axis, and its annual revolution round the Sun, The Astronomical Register (3) 29 (1865), Appendix, A6.

[113] H. Perigal: Polygonal sections, The Athenæum, No. 2093, December 7 (1867), 768.

[114] H. Perigal: Polygonal sections of the circle - The pentagon and heptagon, Ecc, The Mechanics' Magazine, (87) 13 December (1867), 397.

[115] H. Perigal: Polygonal sections of the circle - The pentagon and heptagon, 60 , English Mechanic and Mirror of Science (6) 143 (1867), 285.

[116] H. Perigal: Kinematic curves, The Astronomical Register (6) 61 (1868), 30. 
[117] H. Perigal: Revolution and rotation illustrated by ball and compasses, The Astronomical Register (7) 75 (1869), 68-69.

[118] H. Perigal: Revolution and rotation, English Mechanic and Mirror of Science (10) 251 (1870), 434.

[119] H. Perigal: [Letter to the Editor], The Quarterly Journal of the Amateur Mechanical Society (1) 3 (1871), 110-111.

[120] H. Perigal: Kinematic astronomy of the past and future, 1871, 3 pp.

[121] H. Perigal: On geometrical dissections and transformations, Messenger Math. (2) 19 (1872), 103106.

[122] H. Perigal: The geometric chuck, The Quarterly Journal of the Amateur Mechanical Society (1) 7 (1872), 292-294.

[123] H. Perigal: Geometrical dissections and transformations. No. II, Messenger Math. (4) 43 (1874), 103-104.

[124] H. Perigal: On a kinematic paradox, Proc. Lond. Math. Soc. (10) 142 (1878), 28.

[125] H. Perigal: Effects of compound circular motion, 1881, 8 pp.

[126] H. Perigal: Miscellaneous physical and mathematical papers, Spottiswoods and Co., London, 18401889.

[127] H. Perigal: Graphic demonstrations of geometric problems (On geometric dissections and transformations), Bowles and Sons, London, 1891.

[128] H. Perigal: Phases of Perigal's retrogressive kinematic parabola derived from the circle, Bowles and Sons, London, 1894.

[129] T. L. Porter: Camera Club, The British Journal of Photography (44) 1928 (1897), 254.

[130] R. A. Proctor: Revolution and rotation, English Mechanic and Mirror of Science (10) 252 (1870), 456.

[131] R. A. Proctor: On some astronomical paradoxes, Belgravia (33) 130 (1877), 162-182.

[132] R. A. Proctor: A treatise on the cycloid and all forms of cycloidal curves and on the use of such curves in dealing with the motions of planets, comets, $\mathscr{G c}$ and of matter projected from the sun, Longman, Green, and Co., London, 1878.

[133] L. J. Putnam: The harmonic pattern function: A mathematical model integrating synthesis of sound and graphical patterns, PhD thesis, University of California, Santa Barbara, 2012.

[134] Royal Astronomical Society: Obituary Notice - Henry Penigal, Monthly Notices Royal Astron. Soc. (59) 5 (1899), 226-228.

[135] Royal Institution: Notices of the Proceedings at the Meetings of the Members of the Royal Institution, with Abstracts of the Discourses Delivered at the Evening Meetings, Vol. 1 (1851-1854), W. Nicol, London, 1854.

[136] Royal Institution: Notices of the Proceedings at the Meetings of the Members of the Royal Institution of Great Britain, with Abstracts of the Discourses Delivered at the Evening Meetings, Vol. 14 (1893-1895), William Clowes and Sons, London, 1896.

[137] R. Riccardi: Apparatus for verification of the Pythagorean theorem, US Patent 4,137,652. 1979.

[138] Royal Aeronautical Society: Obituart Notice - Mr. H. Perigal, The Aeronautical Journal (2) 7 (1898), 67.

[139] Royal Meteorological Society: Correspondence and notes - Complimentary dinner to Mr. H. Perigal, Q. J. R. Meteorol. Soc. (19) 86 (1893), 154.

[140] Royal Meteorological Society: Report of the Council for the year 1893, Q. J. R. Meteorol. Soc. (20) 90 (1894), 92-125.

[141] Royal Meteorological Society: Proceedings of the Meeting of the Society. June 15, 1898, Q. J. R. Meteorol. Soc. (24) 108 (1898), 262.

[142] Royal Meteorological Society: Obituary Notice - Henry Penigal, Q. J. R. Meteorol. Soc. (25) 111 (1899), 207, 223-225.

[143] Royal Meteorological Society: Henry Perigal, F.R.A.S. (Treasurer 1853-1898), Q. J. R. Meteorol. Soc. (25) 111 (1899), Frontispiece.

[144] Royal Meteorological Society: The President's "At Home," 70 Victoria Street, Westminster May 16, 1899, Q. J. R. Meteorol. Soc. (25) 112 (1899), 334-337.

[145] Royal Microscopical Society: Proceedings of the Society, J. Royal Microscopical Soc. (16) 6 (1896), 702-710.

[146] Royal Microscopical Society: Proceedings of the Society, J. Royal Microscopical Soc. (18) 4 (1898), 494-495.

[147] Royal Society: List of candidates for election into the Society, Abstracts of the Papers Communicated to the Royal Society of London, Vol. 6, 1850-1854, p. 289.

[148] Royal Society: List of candidates for election into the Society, Proceedings of the Royal Society of London, Vol. 7, 1854-1855, pp. 8, 291. 
[149] Royal Society: The Royal Society. Conversazione May 14th 1890. Burlington House, The Royal Society, London, 1890.

[150] Satellite: The moon's motion, The Astronomical Register (8) 91 (1870), 158.

[151] L. Scales: Henry Perigal, the respected crank, The Royal Institution Blog (December, 2014). https://www.rigb.org/blog/2014/december/henry-perigal (accessed 02-07-2020)

[152] G. B. Shaw: The conflict between science and common sense, The Humane Review (1) 1 (1900), $3-15$.

[153] G. B. Shaw: Platform and pulpit, edited with an introduction by Dan H. Laurence, Rupert Hart-David, London, 1962.

[154] G. B. Shaw: Shaw. An Autobiography, 1898-1950. The Playwright Years, Weybright and Talley, New York, 1970.

[155] A. W. Siddons: Perigal's dissection for the theorem of Pythagoras, Math. Gaz. (16) 217 (1932), 44.

[156] J. Steel: The moon does rotate on her own axis, The English Journal of Education (11) 123 (1857), 83-84.

[157] S. M. Stewart: A cabinet of curiosities, Am. J. Phys. (89) 1 (2021), 10.

[158] J. Symons: The moon has no rotary motion, The Times (London), April 8, 1856, p. 5.

[159] J. Symons: The moon's motion, The Times (London), April 12, 1856, p. 5.

[160] J. Symons: The moon controversy, The Times (London), December 13, 1856, p. 9.

[161] J. C. Symons: Lunar motion. The whole argument stated, and illustrated by diagrams; with letters from the Astronomer Royal and others, The English Journal of Education (10) 114 (1856), 253275. Reprinted as J. C. Symons: Lunar motion. The whole argument stated, and illustrated by diagrams; with letters from the Astronomer Royal and others, Groombridge and Sons, London, 1856.

[162] J. C. Symons: On the reasons for describing the moon's motion as a motion about her axis, The English Journal of Education (10) 118 (1856), 427-432.

[163] W. Teasdale: Lantern as an educational tool, The British Journal of Photography (30) 1227 $(1883), 680$

[164] W. Teasdale: Preparation of linear scientific diagrams, The Journal of the Camera Club (8) 96 (1894), 93-94.

[165] J. Timbs (Editor): The year-book of facts in science and art, David Bogue, London, 1845.

[166] Various (T. M. Goodeve; Cam; A Cambridge Wrangler; A Wrangler; S.; J. R. Crawford; The Man in the Moon): The moon's rotation [Letters to the Editor], The Times (London), April 9, 1856, p. 5.

[167] Various (F. I.; J. Symons; E. Hopkins; Rota Tota; R. Wilson; W. Adolph; W. Hawker Langley; Amicus; Vindex; C. Hopkins; J. R. Crawford; G. MacDonell; A. F. Mackintosh; C. Agnew; M. Ker; S. A. Good; T. C. Simon): Does the moon rotate on its own axis? The moon's motion [Letters to the Editor], The English Journal of Education (10) 113 (1856), 216-226.

[168] Various (J. Symons; S. A. Good): Lunar motion defined. The moon's motion. Lunar motion. The moon's motion [Letters to the Editor], The English Journal of Education (10) 116 (1856), $337-343$.

[169] Various (Argus; An Enquirer; Oculi Ambo): The moon controversy. The Moon's axial rotation [Letters to the Editor], The Astronomical Register (2) 14 (1864), 41-42.

[170] Various (W. R. Dawes; J. R.; S. B. K.; Another Enquirer; Cyclops): The moon controversy [Letters to the Editor], The Astronomical Register (2) 15 (1864), 61-64.

[171] Various (The Editor; An Analyst): The moon controversy [Editorial comment. Letter to the Editor], The Astronomical Register (2) 16 (1864), 86.

[172] Various (An Enquirer; R. C. Hubbersty; An Engineer; Oculi Ambo; M. A.; J. G.; Nauticus; I. M. Simkiss; E. Hopkins; W. R. Dawes; Legislator; An Amateur; Cui Lumen Ademptum; The Man in the Moon): The moon controversy [Letters to the Editor], The Astronomical Register (2) 17 (1864), 112-120.

[173] Various (S. B.; J. T. Slugg; Query; J. Reddie; Your Constant Reader; D. Y. C.; A. W. Deey; A. L. S.): The moon controversy [Letters to the Editor], The Astronomical Register (2) 18 (1864), 136-143.

[174] Various (P.; Gamma; T. H.; Analyst; S. B. K.): The moon controversy [Letters to the Editor], The Astronomical Register (2) 19 (1864), 170-172.

[175] Various (E. Hopkins; J. Reddie; Q. E. D.; One Who is Moon-Stricken): On the misapplication of scientific terms. The motion of the moon: correspondence between Mr. Reddie and the Astronomer Royal. The moon controversy [Letters to the Editor], The Astronomical Register (2) 20 (1864), 187-192. 
[176] Various (W. R. Dawes; W.; H.): On the moon's rotation [Letters to the Editor], The Astronomical Register (2) 21 (1864), 215-220.

[177] Various (An Enquirer; N. S. Godfrey): The moon controversy [Letters to the Editor], The Astronomical Register (2) 22 (1864), 242-244.

[178] Various (Nauticus; W. R. Dawes): The moon controversy. On the moon's rotation [Letters to the Editor], The Astronomical Register (2) 23 (1864), 267-272.

[179] Various (F. Bird; Query; An Enquirer; W. Little; Nauticus): The moon controversy. The moon controversy: and something new! [Letters to the Editor], The Astronomical Register (2) 24 (1864), 297-300.

[180] Various (W. R. Dawes; P.; Academicus): On the moon's rotation. The moon controversy [Letters to the Editor], The Astronomical Register (3) 25 (1865), 17-20.

[181] Various (W. L. Banks; Nauticus; W. M.; W. Little): Rotation of satellites. The register, the sun and the moon. The moon controversy [Letters to the Editor], The Astronomical Register (3) 26 (1865), 48-51.

[182] Various (Mathematicus; W. M.): The moon controversy [Letters to the Editor], The Astronomical Register (3) 29 (1865), 142-144.

[183] Various (P. G. L.; J. H. J.): Rotation or non-rotation of the moon [Letters to the Editor], The Astronomical Register (7) 76 (1869), 91-93.

[184] Various (A. W. Deey; Amateur): The moon's motion [Letters to the Editor], The Astronomical Register (8) 88 (1870), 79-80.

[185] C. V. Walker: Royal Astronomical Society Club, The Observatory, A Monthly Review of Astronomy (1) 7 (1877), 211-212.

[186] D. A. Wells: Things not generally known: A popular hand-book of facts not readily accessible in literature, history, and science, D. Appleton and Company, New York, 1857.

[187] C. T. Williams: Jubilee celebrations, Q. J. R. Meteorol. Soc. (26) 115 (1900), 192-197.

[188] W. M.: The moon controversy, The Astronomical Register (3) 31 (1865), Appendix.

Seán M. Stewart, after leaving Australia, taught mathematics for many years to engineers in Kazakhstan and the United Arab Emirates. He now lectures at King Abdullah University of Science and Technology in Saudi Arabia. He has always found it hard to resist the challenge of a definite integral and is the author of How to integrate it: A practical guide to finding elementary integrals published by Cambridge University Press.

Division of Physical Sciences and Engineering, King Abdullah University of Science and Technology (KAUST), Thuwal 23955-6900, SAudi Arabia.

E-mail address: sean.stewart@physics.org 